OPEN ACCESS

Edited by:

Maria Perticone,

University of Magna Graecia, Italy

Reviewed by:

Muhammad Tarek Abdel Ghafar,

Tanta University, Egypt

Richard Yang Cao,

Shanghai Xuhui Central

Hospital, China

*Correspondence:

Connie W. Tsao

ctsao1@bidmc.harvard.edu

Specialty section:

This article was submitted to General Cardiovascular Medicine,

a section of the journal

Frontiers in Cardiovascular Medicine

Received: 13 May 2021 Accepted: 30 September 2021

Published: 08 November 2021

Citation:

Angoff R, Mosarla RC and Tsao CW (2021) Aortic Stiffness: Epidemiology,

Risk Factors, and Relevant

Biomarkers.

Front. Cardiovasc. Med. 8:709396

doi: 10.3389/fcrm.2021.709396

\section{Aortic Stiffness: Epidemiology, Risk Factors, and Relevant Biomarkers}

\author{
Rebecca Angoff ${ }^{1}$, Ramya C. Mosarla ${ }^{2}$ and Connie W. Tsao ${ }^{1 *}$ \\ ${ }^{1}$ Cardiovascular Division, Department of Medicine, Beth Israel Deaconess Medical Center, Boston, MA, United States, \\ ${ }^{2}$ Division of Cardiology, Department of Medicine, New York University Langone Health, New York, NY, United States
}

Aortic stiffness (AoS) is a maladaptive response to hemodynamic stress and both modifiable and non-modifiable risk factors, and elevated AoS increases afterload for the heart. AoS is a non-invasive marker of cardiovascular health and metabolic dysfunction. Implementing AoS as a diagnostic tool is challenging as it increases with age and varies amongst races. AoS is associated with lifestyle factors such as alcohol and smoking, as well as hypertension and comorbid conditions including metabolic syndrome and its components. Multiple studies have investigated various biomarkers associated with increased AoS, and this area is of particular interest given that these markers can highlight pathophysiologic pathways and specific therapeutic targets in the future. These biomarkers include those involved in the inflammatory cascade, anti-aging genes, and the renin-angiotensin aldosterone system. In the future, targeting AoS rather than blood pressure itself may be the key to improving vascular health and outcomes. In this review, we will discuss the current understanding of AoS, measurement of AoS and the challenges in interpretation, associated biomarkers, and possible therapeutic avenues for modulation of AoS.

Keywords: aortic stiffness, pulse wave velocity, cardiovascular health, risk factors, biomarkers

\section{INTRODUCTION}

Aortic stiffness (AoS) is a measure of the elasticity of the blood vessel wall, and elevated AoS may result from and contribute to increased stress on the vessel walls. It is a non-invasive method of measuring maladaptive change and remodeling to aortic properties and is a promising marker of subclinical disease. Its measurement is based on principles of physics. The arterial tree has varying mechanical properties along its length, primarily determined by different contributions of collagen and elastin to its structure, in addition to varying degrees of modulation by smooth muscle. Pulse waves generated from pulsatile hemodynamics of the cardiac cycle travel down the large conduit arteries to the mid-sized arteries where they incur increased resistance due to branch points and increased arterial tone. The incident waves are then reflected back toward the central arteries from the periphery. The stiffness of the central conduit arteries determines the velocity with which the reflected waves return, with increased AoS resulting in more rapid propagation of reflected waves, determining the measured pulse wave velocity (PWV) (1). Pathologically increased AoS allows waves reflected from the periphery to return in phase with cardiac systole, augmenting central systolic pressure and increasing hemodynamic load on the left ventricle. AoS is able to capture a unique measure of central hemodynamics not reflected by 
simply the blood pressure alone, likely explaining the ability of carotid-femoral PWV (cfPWV) to serve as an independent predictor of cardiovascular outcomes. Further, the processes implicated in AoS, which include activation of oxidative stress pathways and inflammation may be reflective of underlying vascular risk (2).

The purpose of this review is to discuss the clinical implications of AoS, its measurements including PWV and augmentation index (AI), and the factors that contribute to and alter AoS. We will also review AoS involvement in disease processes as well as biomarkers involved in AoS. The goal is to gain a better understanding of AoS as a subclinical marker of chronic disease.

\section{CLINICAL SIGNIFICANCE}

Stiffening of the aorta is a marker of subclinical disease and has been demonstrated to precede the onset of hypertension in a longitudinally followed cohort (3). Earlier studies first implicated elevated PWV to be associated with atherosclerosis (4) and as a predictor of worse cardiovascular outcomes and mortality in high-risk conditions such as diabetes mellitus (DM), chronic kidney disease, and hypertension, as well as coronary artery disease post-myocardial infarction (5-7). AoS was later demonstrated in healthy community dwelling individuals to predict incident events including coronary disease, heart failure, stroke, and cardiovascular mortality independently of adjustment for cardiovascular risk factors (8-11). Further, there is evidence that AoS reflects the presence of composite end-organ damage and has been shown to have superior prognostic value to measurements of office and ambulatory systolic blood pressures in patients with advanced kidney disease (12).

The adverse outcomes related to elevated AoS suggested by the prior studies have been corroborated and further evaluated through meta-analyses. In such a 2010 study by Vlachopoulos et al. an increase in PWV of $1 \mathrm{~m} / \mathrm{s}$ conferred an increased risk of cardiovascular events, cardiovascular mortality, and allcause mortality (13). Moreover, a meta-analysis of over 17,000 participants showed that a 1-standard deviation difference in log-transformed cfPWV was associated with an increased risk of future cardiovascular events over 5 years even after adjusting for more traditional risk factors; furthermore, this same metaanalysis showed that using cfPWV in addition to traditional risk factors was able to reclassify patient risk for cardiovascular disease (CVD) for those who had an intermediate 10 year CVD risk (14). Therefore, by measuring AoS in patients, practitioners may be able to detect patients at risk for CVD at an early, subclinical stage. This early detection may provide the opportunity for early intervention, patient education on risk factors, and potentially help to decrease the incidence of overt disease.

\section{MEASUREMENT}

Several modalities are available to measure AoS by PWV including recording the pulse waves by a tonometer transducer, standard blood pressure cuff, doppler ultrasound, and magnetic resonance imaging (MRI) (15). The transducer methods consist of placing a tonometer over the carotid and femoral arteries and monitoring an ECG signal for timing of the pressure waveforms. These methods have historically been the gold standard but can be a challenging learning curve for the operator. Thus, there has been increased interest in comparing the various AoS measurement methods to determine which is most accurate and easiest to implement. Pulse wave doppler ultrasound allows measurement of AoS without the need for a specific measurement device, is quicker, and has been shown to be comparable to transducer methods $(16,17)$. While blood pressure cuff measured cfPWV may be easier to acquire than the doppler approach, it often requires correction (18). MRI based techniques also offer promise due to their ability to directly and accurately visualize path-length and ability to quantify AoS in more proximal aortic segments but lack practicality (19).

cfPWV is the gold standard measure of aortic wall stiffness (2). cfPWV is obtained via transcutaneous measurement of the pressure waveform at the common carotid artery and at the femoral artery by either probes or blood pressure cuffs; alternatively, this can be measured from Doppler or MRI flow waveforms (20). The distance between the two surface sites and the time delay between the waveforms is used to determine the velocity component (2). Figure 1 depicts how the cfPWV is calculated. It is important to note that blood pressure and PWV are closely intertwined with higher mean arterial pressures correlated with increased AoS $(15,22)$.

However, there are additional challenges to measuring cfPWV. The surface distance between carotid and femoral sites of measurement may not represent true arterial pathlength, especially in patients with obesity. Therefore, proposed correction factor equations account for these systematic inaccuracies such as multiplying the distance from the carotid artery to the femoral artery by 0.8 (23). In addition, there are challenges with measuring pressure waveforms in obese patients and in controlling for existing atherosclerotic disease in vessels. Furthermore, conditions during time of measurements such as patient positioning, temperature in the room, and white coat hypertension can all confound the results (2). Brachial PWV methods also exist, but because of PWV amplification in peripheral arteries, it is considered a less reliable measure of central artery stiffness (24).

Augmentation index (AI) is another measurement of AoS (Figure 1). It is measured by dividing the augmentation pressure by the pulse pressure and multiplying by 100 to provide a number (percentage). AI is a stronger predictor of left ventricular mass reduction in response to lowering the blood pressure compared to other more conventional measures such as brachial blood pressure (25), and increased AI is independently associated with increased cardiovascular events in those undergoing percutaneous coronary interventions (26). Furthermore, more recent data has shown that higher augmentation index is associated with poor exercise capacity after heart transplant (27). However, AI is impacted by other factors such as age, systolic blood pressure, heart rate, left ventricular ejection time, and height to a greater extent than PWV $(28,29)$. Therefore, PWV, and in particular cfPWV, is used more often in trials. 


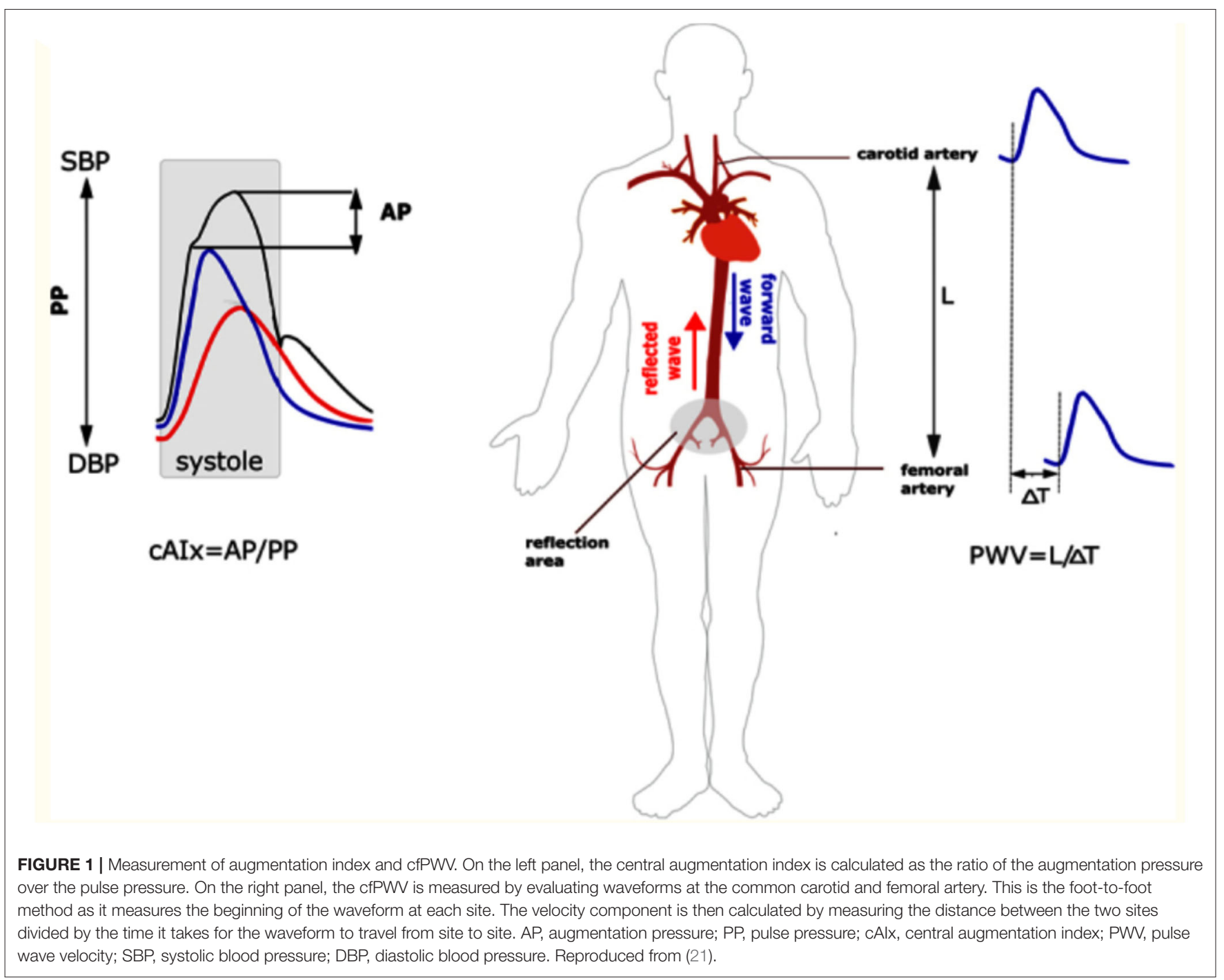

\section{NORMATIVE VALUES AND IMPACT OF DEMOGRAPHICS}

Despite having known prognostic implications distinct from traditional cardiovascular risk factors, the clinical use of cfPWV has been limited due to lack of widespread use of population specific reference ranges. The 2007 ESC/ESH guidelines proposed a cut-off value of $12 \mathrm{~m} / \mathrm{s}$ for elevated AoS based on clinical outcome data (30). Furthermore, multiple studies have sought to establish reference ranges for PWV. The Reference Values for Arterial Stiffness Collaboration Database was one of the first large-scale efforts to establish reference ranges for cfPWV in 16,867 European individuals across 13 centers (31). A subset of 11,092 individuals without prevalent CVD or use of anti-hypertensive or lipid-lowering medications were used to draw reference values presented in Table 1. However, a challenge with creating normative values is that experienced laboratories are needed for cfPWV measurement, and disparate measurement devices and methodologies can produce a variance in PWV affecting generalizability even within the same patient (32).

\section{AGE, SEX, AND RACE}

\section{Age}

A rise in AoS with age has been well-described in large, diverse groups free of clinical CVD (31, 33-35). Central artery stiffness results in a reduced arterial reservoir effect, augmenting pressure during systole and diminishing it during diastole (36). This is thought to be one mechanism for the observed age-related increase in systolic blood pressure and decline in diastolic blood pressure, which lead to adverse ventricular and vascular hemodynamics, poor cardiac perfusion, and cardiac remodeling $(37,38)$.

Several mechanisms may contribute to age-related arteriosclerosis. Intrinsic remodeling of arteries has been demonstrated with increasing intima media thickness with age (39). Changes in the mechanical properties of the vascular 
TABLE 1 | Distribution of pulse wave velocity (PWV) values $(\mathrm{m} / \mathrm{s})$ in the reference value population (11,092 subject) according to age and blood pressure category.

\begin{tabular}{|c|c|c|c|c|c|}
\hline Age category (years) & \multicolumn{5}{|c|}{ Blood pressure category } \\
\hline ( $\pm 2 S D)$ & & & & & \\
\hline$<30$ & $6.1(4.6-7.5)$ & $6.6(4.9-8.2)$ & $6.8(5.1-8.5)$ & $7.4(4.6-10.1)$ & $7.7(4.4-11.0)$ \\
\hline 30-39 & $6.6(4.4-8.9)$ & $6.8(4.2-9.4)$ & $7.1(4.5-9.7)$ & $7.3(4.0-10.7)$ & $8.2(3.3-13.0)$ \\
\hline $50-59$ & $7.6(4.8-10.5)$ & $8.4(5.1-11.7)$ & $8.8(4.8-12.8)$ & $9.6(4.9-14.3)$ & $10.5(4.1-16.8)$ \\
\hline $60-69$ & $9.1(5.2-12.9)$ & $9.7(5.7-13.6)$ & $10.3(5.5-15.1)$ & $11.1(6.1-16.2)$ & $12.2(5.7-18.6)$ \\
\hline$\geq 70$ & $10.4(5.2-15.6)$ & $11.7(6.0-17.5)$ & $11.8(5.7-17.9)$ & $12.9(6.9-18.9)$ & $14.0(7.4-20.6)$ \\
\hline \multirow{2}{*}{\multicolumn{6}{|c|}{$\begin{array}{l}\text { PWV as median } \\
\text { (10th-90th percentile) }\end{array}$}} \\
\hline & & & & & \\
\hline$<30$ & $6.0(5.2-7.0)$ & $6.4(5.7-7.5)$ & $6.7(5.8-7.9)$ & $7.2(5.7-9.3)$ & $7.6(5.9-9.9)$ \\
\hline $60-69$ & $8.7(7.0-11.4)$ & $9.3(7.6-12.2)$ & $9.8(7.9-13.2)$ & $10.7(8.4-14.1)$ & $12.0(8.5-16.5)$ \\
\hline$\geq 70$ & $10.1(7.6-13.8)$ & $11.1(8.6-15.5)$ & $11.2(8.6-15.8)$ & $12.7(9.3-16.7)$ & $13.5(10.3-18.2)$ \\
\hline
\end{tabular}

Modified from Reference Values for Arterial Stiffness (31).

HTN, hypertension; SD, standard deviation.

media are also observed, with maladaptive remodeling with increased deposition of collagen (40). Age related arteriosclerosis that is independent of atherosclerosis is supported by the strong independent association between age and cfPWV that persists in those without aortic calcifications (41). The cumulative exposure to vascular risk factors including DM also contributes to increases in AoS with age (42).

\section{Sex}

The relationship between sex and AoS is complex and varies with age. Whereas pre-pubescent females have higher PWV than pre-pubescent males, this difference is abrogated postpuberty as the average PWV in females decreases but PWV in males increases (43). In the Jackson Heart Study, while adult men were more likely to have elevated cfPWV in the overall cohort, women had steeper rise in both cfPWV and forward wave amplitude with age $>60$ (35). Brachial-ankle PWV (baPWV) has been shown to be similar in males and females until about age 50-60 years old, at which point there is a greater proportional increase in female baPWV (44). This accelerated increase in the baPWV around age 50-60, when females are postmenopausal, provides further evidence that there is a hormonal component to the sex differences in AoS. Furthermore, when corrected for age and blood pressure, middle aged females with metabolic syndrome had higher aortic PWV as compared to males, again supporting the role of sex the relationship of age with PWV (45).

The mechanism behind sex differences in AoS may be related to downstream effects of sex hormones. Men with acquired hypogonadism have higher PWV compared to normal men, and treatment with testosterone therapy helps to lower PWV, supporting a possible role for testosterone in lowering AoS (46). Indeed, in animal models, testosterone induces endotheliumindependent vasodilation of arterial beds (47). Sex hormones in women also seem to play roles in modulating AoS. Decreases in estradiol with menopause are associated with a proinflammatory state, which may be a cause of elevated AoS in women after menopause (48). Furthermore, female sex steroids such as 17 beta estradiol and progesterone promote elastin deposition, and thus withdrawal following menopause may also contribute to increased AoS during this time period (49).

\section{Race}

African Americans (AA) suffer a disproportionately increased risk of CVD, hypertension, and microvascular dysfunction compared to whites, highlighting the disparities in vascular morbidity and mortality (50-52). Data suggests that these differences may be driven by a difference in risk factor burden, sociodemographic factors including income, as well as intrinsic differences in mechanical properties of blood vessels and baseline AoS (53).

Differences in AoS between AA and whites have been observed in childhood. AA boys as young as 6-8 years old have elevated mean arterial pressure (MAP), intimal media thickness, and cfPWV compared to white boys (54). Sociodemographic factors including education, lower family income, and lower socioeconomic status were all associated with higher PWV (55). However, higher aortic PWV is seen in AA children compared to whites even after adjusting for age, sex, body mass index, mean arterial pressure, and socioeconomic status (56). This difference in AoS among children persists in adults. In the Multi-Ethnic Study of Atherosclerosis of multiple community cohorts, AA had a higher 
prevalence of hypertension and lower aortic distensibility (57). In the Dallas Heart Study, both AA and Hispanic individuals had greater aortic arch PWV independent of cardiovascular risk factors including mean arterial pressure, heart rate, DM, and smoking (58).

However, other studies suggest that there may be confounding variables that account for the differences in AoS among races. In the ELSA-Brasil study, investigators noted that AAs had a higher burden of hypertension, DM, and obesity compared to the other racial groups and had higher unadjusted cfPWV compared to browns and whites who were similar. However, after adjusting for characteristics including mean arterial pressure, age, waist circumference, heart rate, and fasting glucose, the inter-group differences were abrogated. The results of this study indicate that $\sim 40 \%$ of the difference between cfPWV values could be explained by age and mean arterial pressure, suggesting less contribution by race itself to AoS. Though there may be a race-sex interaction in women, with AA and brown women having higher cfPWV than whites particularly in the highest quartiles of cfPWV, the strength of that relationship was much weaker than the effects of MAP and age (59).

Several mechanisms have been proposed to contribute to the differences of AoS among racial/ethnic groups. First, risk factor sensitivity may vary among different racial groups. For example, cfPWV progression is affected by risk factors such as diastolic blood pressure, glucose, and low-density lipoprotein cholesterol in AA women, while it was not in Caucasian women (60). Furthermore, it has been demonstrated that AAs living in the northern hemisphere likely suffer a greater burden of Vitamin D deficiency relative to white counterparts (61). Vitamin $\mathrm{D}$ has been proposed to improve vascular health by suppressing oxidative pathways and the sensitivity to renin-angiotensinaldosterone system (RAAS) mediated remodeling. Vitamin D supplementation has been shown to decrease PWV in AAs with vitamin D deficiency (62). While the paucity of large-scale studies suggests the need for further research to determine the clinical utility of improving Vitamin D to improve vascular health, this modifiable risk factor creates a targetable treatment regimen for AAs.

Generalized endothelial dysfunction has also been posited as a mediator of progressive AoS in AAs compared to whites. Studies have demonstrated that AAs tend to have impaired nitric oxide signaling and thus more endothelial cell dysfunction at baseline and when compared to whites $(63,64)$. This impaired nitric oxide signaling in AAs compared to white Americans has been shown to be present even after adjusting for CVD risk factors, suggesting that impaired vascular function precedes incident disease (65). Whether additional intrinsic differences in the properties of vessels or unmeasured risk factors exist between racial/ethnic groups remains to be determined.

\section{COMORBIDITIES ASSOCIATED WITH AOS}

\section{Hypertension}

Hypertension demonstrates a very strong association with AoS compared to other cardiometabolic risk factors studied. A major shift has occurred regarding the understanding of directionality between hypertension on AoS and vice versa. The initial paradigm posited that arterial stress induced by elevated pressure and pulsatility-mediated breaks in elastin led to maladaptive remodeling by inducing inflammation $(1,66$, 67). Both baseline blood pressure and blood pressure variability have been linked to increased vascular stiffness (68). Higher blood pressure variability is thought to promote vascular smooth muscle cell proliferation and atherosclerosis as well as increase oscillatory wall stress $(69,70)$. This increased variability may lead to increased AoS which in turn, with stiffer arteries, may increase blood pressure (71).

Clinical and experimental studies have demonstrated that the relationship between hypertension and AoS is interdependent (72-74). Elevated AoS preceding the development of overt hypertension has been demonstrated in population-based studies $(3,75)$. Additionally, Weisbrod et al. evaluated the temporal relationship between AoS and hypertension in a mouse model of diet induced obesity, demonstrating that AoS increased within 1 month while hypertension evolved in 5 months (76). Increased AoS and blood pressure were reversed with weight loss. Understanding this temporal relationship is of particular clinical significance, as AoS can be used as a marker for patients that are high risk to develop hypertension, prompting earlier risk factor modification and potential treatment.

\section{Metabolic Syndrome}

While hypertension alone can increase AoS, metabolic syndrome is also associated with increased AoS. Metabolic syndrome is a constellation of disorders consisting of obesity, insulin resistance, hypertension, and dyslipidemia. Investigators from the Bogalusa Heart Study showed that even in asymptomatic, young (ages 2444) subjects, baPWV rose with increasing number of components of the metabolic syndrome (77). Multiple other studies have shown that metabolic syndrome components were associated with elevated PWV (78-80). Investigators of the CRAVE study also showed that patients with both hypertension and dyslipidemia had a four-fold increase in the annual progression of cfPWV compared to controls (80). There is also evidence to suggest that resolving metabolic syndrome is associated with lower PWV compared to those with current metabolic syndrome (81).

\section{Diabetes Mellitus}

Patients with DM are at a high risk for CVD $(82,83)$. Aortic PWV serves as an additional tool to help risk stratify patients as increased PWV has been shown to be associated with CVD in those with DM (84). An interesting dose dependent relationship between level of glucose dysregulation and elevation of cfPWV has also been described (85).

The pathogenesis of AoS in DM is likely to be mediated by the pro-inflammatory milieu generated by metabolic dysregulation and direct damage to the vascular wall. For example, high intake of advanced end glycation products, such as carboxy-methyllysine, have been associated with higher PWVs among those with DM (86). Furthermore, a trial of ALT-711, a non-enzymatic breaker of these products, decreased PWV in the elderly (87). Different genotypes of advanced end glycation products and their 
TABLE 2 | Association of lifestyle risk factors with aortic stiffness.

\begin{tabular}{|c|c|c|c|}
\hline & Population studied & Exposure & Effect \\
\hline \multirow[t]{2}{*}{ Diet } & Adults $20-59$ years of age & Salt consumption (varied) & $\begin{array}{l}\text { An increase in urinary sodium excretion by }>100 \text { mmol over a } \\
24-\mathrm{h} \text { period is associated with increased systolic pressures } \\
\text { by } 3-6 \mathrm{~mm} \mathrm{Hg} \text { and increased diastolic pressures by } 0-3 \mathrm{~mm} \\
\mathrm{Hg}(90)\end{array}$ \\
\hline & $\begin{array}{l}11 \text { adults aged } 60 \pm 2 \text { years with } \\
\text { elevated } \mathrm{BP}(139 \pm 2 \text { over } 83 \pm 2 \\
\mathrm{mmHg})\end{array}$ & $\begin{array}{l}\text { Low sodium }(77 \pm 2 \mathrm{mmol} / \mathrm{d}) \mathrm{vs} \text {. } \\
\text { normal sodium }(144 \pm 7 \mathrm{mmol} / \mathrm{d})\end{array}$ & $\begin{array}{l}\text { Low sodium group with } 17 \% \text { reduction in aortic PWV } \\
\text { compared to normal sodium ( } 7 \pm 0.40 \text { vs. } 8.43 \pm 0.36 \mathrm{~m} / \mathrm{s}, p \\
=0.001) \text { (91) }\end{array}$ \\
\hline \multirow[t]{3}{*}{ Exercise } & $\begin{array}{l}\text { Endurance trained males age } 69 \\
\pm 2.5 \text { years }\end{array}$ & $\begin{array}{l}\text { Fitness level: VO2 max at least } 1 \\
\text { SD above age matched sedentary } \\
\text { counterparts }\end{array}$ & $26 \%$ decrease in Aortic PWV relative to peers their age (92) \\
\hline & $\begin{array}{l}\text { Pre-menopausal women aged } 31 \\
\pm 1 \text { years and post-menopausal } \\
\text { women age } 59 \pm 2 \text { years }\end{array}$ & $\begin{array}{l}6 \pm 1 \text { hour/week of endurance } \\
\text { exercise }\end{array}$ & $\begin{array}{l}\text { No significant difference in aortic PWV or Al between pre and } \\
\text { post-menopausal women with exercise (suggesting age } \\
\text { related increase in AoS is halted by exercise) (93) }\end{array}$ \\
\hline & $\begin{array}{l}\text { Systematic review/meta-analysis } \\
\text { of } 14 \mathrm{RCT} \text { of adults with } \\
\text { pre-hypertension and } \\
\text { hypertension }\end{array}$ & $\begin{array}{l}\text { Exercise types: } \\
\text { aerobic/endurance, dynamic } \\
\text { resistance, isometric resistance, } \\
\text { combined exercise }\end{array}$ & $\begin{array}{l}\text { Exercise significantly reduced PWV by } 0.76 \mathrm{~m} / \mathrm{s}(\mathrm{Cl} \\
1.05-0.47)(94)\end{array}$ \\
\hline \multirow[t]{3}{*}{ Smoking } & $\begin{array}{l}\text { Healthy adults } 33 \pm 6 \text { years of } \\
\text { age }\end{array}$ & $\begin{array}{l}\text { Acute: } 5 \text { min after smoking } 1 \\
\text { cigarette }\end{array}$ & FMD \% decreased from $13.5 \pm 5$ to $6.9 \pm 4 \%(95)$ \\
\hline & Adults $15-57$ years of age & Chronic: $1-75$ pack years & $\begin{array}{l}\text { FMD } 10 \pm 3.3 \%(4-22 \%) \text { in controls vs. } 4 \pm 3.9 \%(0-17 \%) \text { in } \\
\text { smokers; FMD is inversely related to the duration of } \\
\text { smoking (96) }\end{array}$ \\
\hline & Males 30-64 years of age & $\begin{array}{l}\text { Non-smokers, former smokers, } \\
\text { and current smokers }\end{array}$ & $\begin{array}{l}\text { Men who quit smoking }<1 \text { year prior had elevated } \mathrm{Al}(\beta 3.94 \text {, } \\
\text { SE } 1.54, p=0.011 \text { ) similar to current smokers }(\beta 4.39, \mathrm{SE} \\
0.74, p<0.001) \text { compared to non-smokers; those that quit } \\
1-<10 \text { years prior with Al similar to non-smokers ( } \beta 1.87, \mathrm{SE} \\
0.94, p<0.047)(97)\end{array}$ \\
\hline E-cigarettes & Adults $30 \pm 8$ years of age & $\begin{array}{l}5 \text { min of usage and } 30 \mathrm{~min} \text { of } \\
\text { usage }\end{array}$ & $\begin{array}{l}\text { Smoking over } 5 \text { min increased cfPWV by } 0.19 \text { m/s after } \\
15 \text { min; over } 30 \text { min increased cfPWV by } 0.36 \mathrm{~m} / \mathrm{s}(98)\end{array}$ \\
\hline \multirow[t]{2}{*}{ Alcohol } & Males $40-80$ years of age & $\begin{array}{l}\text { 4-10, 11-21, and 22-58 } \\
\text { drinks/week }\end{array}$ & $\begin{array}{l}\text { Compared to those consuming 0-3 drinks per week; } \\
\text { decreased cfPWV by } 0.77 \mathrm{~m} / \mathrm{s} \text { (4-10 drinks), } 0.57 \mathrm{~m} / \mathrm{s} \\
\text { (11-21 drinks), } 0.14 \mathrm{~m} / \mathrm{s}(22-58 \text { drinks) (99) }\end{array}$ \\
\hline & $\begin{array}{l}\text { Post-menopausal women } 50-74 \\
\text { years of age }\end{array}$ & $\begin{array}{l}\text { 1-3, 4-9, 10-14, and 15-35 } \\
\text { drinks/week }\end{array}$ & $\begin{array}{l}\text { Compared to non-drinkers: those consuming } 1-3,4-9 \text {, } \\
10-14 \text {, and } 15-35 \text { drinks/week had the following difference in } \\
\text { mean cfPWV } 0.044(95 \% \mathrm{Cl}-0.47-0.56),-0.085(95 \% \mathrm{Cl} \\
-0.59-0.43),-0.869(95 \% \mathrm{Cl}-1.44-0.29) \text {, and }-0.225 \\
(95 \% \mathrm{Cl}-0.98-0.53) \mathrm{m} / \mathrm{s}(100)\end{array}$ \\
\hline
\end{tabular}

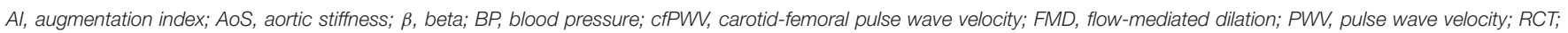
randomized control trial; $S D$, standard deviation; $S E$, standard error.

receptors have also been associated with increased blood pressure and AoS in patients with DM (88). Therefore, modulation of advanced end glycation products remains an interesting target to halt disease progression. Furthermore, increased glucose may lead to increased activity of RAAS and thus the detrimental consequences as described in the section on RAAS below (89).

\section{LIFESTYLE RISK FACTORS}

The association of lifestyle risk factors with AoS detailed below are summarized in Table 2.

\section{Alcohol}

Much of the evidence for the association of alcohol with AoS is data derived from self-reported alcohol consumption in cross-sectional epidemiology studies. Interestingly, evidence suggests there may be a J shaped relationship of alcohol use to central aortic hemodynamics, with more favorable measures among those with light to moderate consumption compared with negligible and heavy drinkers. In young individuals, those who reported light alcohol consumption, 2-6 drinks per week, had lower central blood pressure than those who drank lower or greater amounts (101). Similar findings have been reported in middle aged to older adults. In men aged $40-80$ years old, those who drank moderate to large amounts of 4-10 and 1121 drinks per week had lower PWV than those who drank more or less than these groups (99). Additionally, in post-menopausal women aged 50-74 years, moderate alcohol intake was inversely related to PWV (100). Furthermore, in controlled experiments, alcohol ingestion appears to acutely decrease AoS. Even drinking 200 or $350 \mathrm{cc}$ of beer leads to decreased baPWV and cfPWV compared to controls (102). There are many proposed mechanisms as to why low doses of alcohol can be beneficial 
to the heart such as by increasing HDL, insulin sensitivity, and decreasing oxidative stress (103). More acutely, small amounts of alcohol may decrease PWV through alcohol induced increases in nitric oxide (104). Ultimately, future prospective studies will shed light on the ideal alcohol consumption with respect to long-term outcomes and recommended exposure for vascular health.

\section{Smoking}

Smoking is a major modifiable risk factor for CVD (105). One cigarette causes acute increases in brachial and aortic blood pressure, arterial wave reflection, and AoS (106). Even passive smoking has been shown to worsen the elasticity of the aorta (107). Cigarette smoking has been shown to have a dose-response relationship to elevated PWV, which is only reversed after prolonged smoking cessation $>10$ years (108). There is also evidence to suggest that e-cigarettes are detrimental to AoS (98). The effect of cigarettes on AoS may be due to endothelial cell damage and subsequent impaired vasodilatory capacity $(95,96)$. Additional mechanisms appear to be an increase in cholesterol, increased vascular remodeling and arterial calcification, increased vascular tone, and oxidative stress/inflammation (109).

\section{Diet and Physical Activity}

There is a growing body of evidence that lifestyle habits including smoking cessation, diet modification, and exercise/weight loss can reverse AoS (110). It is well-supported that high salt intake leads to higher blood pressures (90) and that reduction in salt intake leads to lower blood pressures (111). Low salt diets similarly have been associated with lower PWV independent of blood pressure (112). Furthermore, in men, over a period of 17.8 years, higher consumption of saturated fatty acids was associated with higher cfPWV and higher consumption of polyunsaturated fatty acids was associated with lower cfPWV (113). Greater dairy consumption, particularly in those with DM, as well as increased intake of vegetables has also been associated with lower AoS (114-116).

Physical activity leads to lower central PWV and age-related increases in PWV can be mitigated by exercise in both men and women $(92,93)$. The Baltimore Longitudinal Study of Aging rigorously phenotyped adults and measured VO2 max in adults aged 21-96 years of age. These investigators demonstrated that with greater age in the entire cohort, augmentation index and aortic PWV increased out of proportion to the blood pressure increase. However, these measures of AoS were lower in endurance trained male athletes (defined by a VO2 max 1 standard deviation above their age matched non-trained controls), compared with sedentary individuals (defined as less than at least $20 \mathrm{~min}$ of aerobic exercise three times weekly) of similar age (92). Similarly, while sedentary post-menopausal women have higher augmentation index and PWV than comparable pre-menopausal women, these measures of AoS were similar in both pre- and post-menopausal active women who were physically active (performed endurance training, actively competing in running races, with average exercise of $6+/-1$ hour of activity per week) (93). The effect of exercise on reducing AoS is thought to relate to exercise induced changes in vessel wall stress, a reduction in vasoconstrictors and ultimately vasodilation via increased nitric oxide activity $(117,118)$. These studies add to the growing body of evidence that improved lifestyle modifications could make a large impact on the development and progression of disease.

\section{BIOMARKERS ILLUMINATING PATHOPHYSIOLOGY AND THERAPEUTICS}

Given the association of AoS with adverse outcomes, serum biomarkers that correlate with AoS allow further insight into mechanisms of AoS, non-invasive detection and monitoring of AoS, and may highlight therapeutic targets. In this section, we will discuss key serum biomarkers that modulate AoS, and the associated evidence for therapies targeting these pathways.

\section{Inflammatory Biomarkers}

The presence of chronic inflammatory and infectious conditions is associated with elevated AoS. In patients with systemic lupus erythematosus, cfPWV was shown to be elevated even when traditional risk stratification categorized patients into low risk for CVD (119). Furthermore, higher aortic PWV has been seen in patients with inflammatory bowel disease and has been associated with disease duration (120). Many other inflammatory conditions have been associated with increased AoS such as rheumatoid arthritis $(121,122)$, psoriatic arthritis $(123,124)$, and Sjogren's syndrome $(125,126)$. The increase in AoS in those with autoimmune disorders and chronic inflammatory diseases is independent of more traditional risk factors and related to disease duration and the elevation in inflammatory markers, suggesting inflammation as a key player in this pathology (127).

Multiple inflammatory biomarkers have been associated with AoS. A prospective study that followed middle-aged Japanese men without hypertension for 9 years demonstrated that sustained elevations in serum C-reactive protein (CRP) were associated with a longitudinal increase in baPWV. Higher baPWV was in turn associated with higher blood pressures during follow-up (128). The accelerated vascular disease in this cohort at relatively low vascular risk suggests that chronic inflammation may contribute to progressive vascular stiffness and dysfunction. Though CRP is associated with several cardiovascular risk factors, models adjusting for these demonstrated a persistent linear association between CRP and AoS in the population-based Rotterdam Study (129). A potential mechanism may lie in endothelial dysfunction: in men with coronary artery disease with forearm blood flow response studied with venous occlusion plethysmography, CRP levels were associated with blunted endothelial vasodilator capacity in models including risk factors (130). Additionally, normalization of CRP levels was associated with improved blood flow response in these individuals. IL- 6 is another inflammatory cytokine that has been shown to be associated with cfPWV in individuals with hypertension (131). Furthermore, there is research establishing a link between polymorphisms on IL-6 with increased cfPWV (132). These studies suggest that inflammation is associated 
with AoS but more studies are needed to fully elucidate the mechanistic relationships.

The relationship between inflammatory states and CVD has been further elucidated by studies that have examined the effect of treatment of inflammatory diseases. Patients with rheumatoid arthritis treated with anti-tumor necrosis factor-a agents have shown significant declines in cfPWV after treatment (133). Furthermore, statins have been shown to decrease AoS in patients with inflammatory joint diseases, suggesting that controlling inflammation and possibly lowering lipids is beneficial in this population (134).

\section{Klotho and Sirtuin-1}

Klotho is predominantly expressed in the kidney and has been described as an anti-aging gene (135). When mice are deficient in Klotho, they have decreased lifespan and calcifications of multiple organs. Haplodeficiency of Klotho in mice leads to increased PWV and hypertension $(136,137)$. The association of Klotho levels with AoS has also been demonstrated in patients with chronic kidney disease (CKD) (138). Klotho appears to directly regulate SIRT1, a gene encoding a NAD+ dependentdeacetylase with anti-inflammatory and anti-oxidant effects and importance in endothelial cell function (139, 140). Klotho

TABLE 3 | Association of serum biomarkers with aortic stiffness.

\begin{tabular}{ll}
\hline Biomarker & Clinical relevance \\
\hline Key biomarkers with independent association with AoS \\
Inflammatory biomarkers & - The presence of conditions like SLE (155), IBD (156), psoriasis \\
& $(157)$, and HIV (158) are linked with high higher risk of CVD \\
CRP & - Associated with insulin resistance (160), carotid intima-media \\
& thickness and markers of atherosclerosis (161)
\end{tabular}

Klotho

- Klotho levels lower in those with renovascular hypertension and essential hypertension compared to healthy controls (163)

- Klotho levels lower in those with significant coronary artery disease (164)

$\begin{array}{ll}\text { Aldosterone } & \text { - Increases insulin resistance, oxidative stress, inflammation (89) } \\ \text { - } & \text { Promotes vascular calcification (165) } \\ \text { Other biomarkers associated } & \text { with Aos } \\ \text { Adipocyte-Fatty-Acid- } & \text { - Elevated levels have been associated with endothelial } \\ \text { Binding protein } & \text { dysfunction in patients with type } 2 \text { diabetes (167) } \\ \text { (A-FABP) } & \text { Elevated levels associated with diastolic dysfunction (168) and } \\ & \text { cardiovascular death (169) } \\ \text { - } & \text { Leptin levels predicted ischemic heart disease in patients with } \\ \text { Leptin } & \text { type } 2 \text { diabetes (172) } \\ & \text { Patients with coronary artery disease have higher levels of } \\ & \text { serum leptin (173) } \\ \text { - } & \text { Released in response to ventricular hypertrophy, inflammation, } \\ \text { - } & \text { Predictor for heart failure or death in patients with an acute Ml } \\ & \text { (178, 179) } \\ \text { - } & \text { Parathyroid hormone is associated with atherosclerosis (182) }\end{array}$

Resistin

- Increased resistin associated with increased risk of heart failure, coronary heart disease, CVD (185)

Uric Acid
- High levels of uric acid associated with acute myocardial infarction (188) cardiovascular events $(189,190)$ stroke (190)

\section{Association with aortic stiffness}

- Elevated PWV in IBD patients (120)

- Elevated carotid Al and PWV in SLE patients (159)

- Sustained elevation in serum CRP correlated with increased baPWV and BP in middle aged Japanese men (128)

- In Chinese general population baseline hs-CRP associated with baPWV (162)

- Haplodeficiency in Klotho in mice led to increased AoS $(136,137)$

- Associated with increased PWV (143)

- Fibronectin accumulation (166)

- In patients with hypertension and metabolic syndrome, increased levels of A-FABP associated with increased cfPWV (170)

- A-FABP levels positively correlated with cfPWV in patients with type 2 diabetes (171)

- Higher leptin levels associated with increased cfPWV in patients with kidney transplants (174) and in geriatric patients on dialysis (175)

- Meta-analysis demonstrated leptin is positively associated with cfPWV (176)

- AoS is associated with NT-proBNP level and MR-proANP months after $\mathrm{Ml}(180,181)$

- Patients with mild hyperparathyroidism had increased cfPWV which then decreased after a thyroidectomy (183)

- cfPWV increased independently with parathyroid hormone in Chinese patients with untreated hypertension (184)

- High levels of resistin associated with increased cfPWV in sample with high prevalence of untreated hypertension/obesity (186)

- Serum resistin is an independent predictor of cfPWV in patients with coronary artery disease (187)

- Association between higher uric acid and cfPWV in men after adjustment for confounders (191)

- Overall positive association between uric acid and cfPWV at adjusted analysis in both males and females (192)

- Serum uric acid is independently associated with cfPWV in post-menopausal women (193)

- Significant association between uric acid cf PWV and carotid radial PWV in young Caucasian population (194)

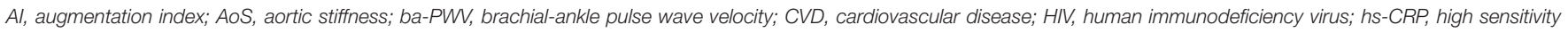
CRP; IBD, Inflammatory Bowel Disease; MI, myocardial infarction; PWV, pulse wave velocity; SLE, Systemic lupus erythematosus. 
haplodeficiency downregulates SIRT1 in arterial endothelial and smooth muscle cells, with associated increased arterial wall collagen deposition and elastin fragmentation, both of which explain the association with AoS (137). Zhou et al. demonstrated that CYP11B2, a rate-limiting enzyme in aldosterone synthesis, is up-regulated in Klotho deficiency, and that treatment with eplerenone reversed increased AoS (141). Thus, another mechanism by which Klotho deficiency may mediate increased AoS is through the aldosterone pathway.

The interaction between Klotho and SIRT1 has illuminated a number of possible targets for therapies that modulate pro-oxidant and pro-inflammatory pathways. Further, improved calcium and phosphate homeostasis may be of increased importance in CKD patients where impaired calcium homeostasis and a pro-inflammatory milieu may accelerate vascular dysfunction. Thus, understanding these mechanisms provides opportunities for possible therapeutic interventions.

\section{RAAS}

The role of RAAS in the progression of AoS is supported by observational studies, clinical studies relating to modulation with therapeutics, biochemical studies demonstrating involvement in vascular remodeling, and mapping of related gene loci.

RAAS-associated AoS is proposed to be due to aldosterone and angiotensin II increased inflammation as well as vasoconstriction from activation of angiotensin I receptors and mineralocorticoid receptors (142). Aldosterone has been shown to be involved in many pathologic processes such as increased insulin resistance, increased oxidative stress, and increased inflammation (89). In multivariable adjusted models, serum aldosterone is linearly associated with PWV in hypertensive patients (143). The importance of RAAS is further highlighted by multiple studies that demonstrate a positive association between cfPWV and polymorphisms in the angiotensin II type 1 receptor (144, 145), angiotensin converting enzyme gene $(146,147)$ as well as in the aldosterone gene (148). Polymorphisms in RAAS may thus contribute to the highly heritable traits of AoS and blood pressure (149). Additional future work may determine the appropriate application of genetic testing to guide detection and management of AoS.

With respect to therapies, inhibiting aldosterone with spironolactone has been shown to decrease collagen density and thus AoS (150). London et al. demonstrated that central systolic blood pressure was decreased to a greater extent with perindopril/indapamide treatment compared to treatment with atenolol, implying a distinct role of RAAS modulation in central hemodynamics (151). This data on the role of RAAS inhibition in AoS may be useful to consider for physicians choosing an anti-hypertensive medication. When compared with atenolol, eplerenone has been shown to decrease AoS, decrease the collagen to elastin ratio, and decrease concentrations of inflammatory markers including MCP-1, basic fibroblast growth factor, and interleukin-10 (152). Furthermore, when comparing atenolol, nebivolol, aliskiren, and quinapril, the RAAS modulating agents demonstrated continued reductions of cfPWV, possibly implicating arterial remodeling rather than modulation of hemodynamics alone
(153). Lastly, non-pharmacologic augmentation to the RAAS system is also important to consider. Decreased salt intake has been shown to decrease AoS independent of blood pressure reductions that may be mediated through RAAS modulation (154).

In addition to the above, other general biomarkers associated with AoS are presented in Table 3.

\section{GENERALIZABILITY AND FUTURE DIRECTIONS}

Despite data illuminating pathways important in AoS pathophysiology and the promising data for their modulation, there has been a paucity of data in this field. Controlled trials thus far have been of relatively small size with short duration, with possibly insufficient follow up time to adequately assess for aortic remodeling and change in AoS (195). However, encouraging data on the prognostic impact of PWV continues to emerge. In the past 2 years, a post-hoc analysis of 8,450 patients in the Systolic Blood Pressure Intervention Trial (SPRINT) demonstrated that reductions in PWV after 1 year of anti-hypertensive therapy were associated with $42 \%$ lower risk of death compared to individuals who did not have reductions in PWV, independent of Framingham Risk Score and blood pressure (196). Additionally, an innovative experiment performed on mice aortas ex vivo used a synthetic peptide targeted to a cytoskeletal protein known to be associated with AoS in human genome wide association studies (197). This study illustrated the proof of concept that such decoy peptides decreased cfPWV, illustrating that approaches targeted to AoS rather than blood pressure per se, may be able to be applied in the future. Ultimately, larger therapeutic trials that target AoS and demonstrate improved outcomes are needed to establish widespread clinical utility of AoS assessment and treatment.

\section{CONCLUSION}

AoS is a precursor to hypertension and an accepted risk factor for CVD independent of blood pressure. Despite its demonstrated prognostic value, thus far broad clinical applicability has been limited by measurement variation in multiple methodologies illustrated, lack of age and blood pressure specific reference values applicable to all populations, and effective therapeutics targeting AoS. AoS may be addressed indirectly through treating several lifestyle risk factors and associated comorbidities. Continued research will help to add to the illustrated biologic pathways of AoS. In the future, novel approaches and applications of existing drugs to specifically target pathways involved in modulating AoS may provide further support to its broader assessment and treatment to improve cardiovascular outcomes.

\section{AUTHOR CONTRIBUTIONS}

RA: drafted manuscript, manuscript editing, and figure copyright permissions. RM: drafted manuscript. CT: manuscript concept and editing. All authors contributed to the article and approved the submitted version. 


\section{FUNDING}

This work was partially supported by NHLBI R03HL145195 and R01HL155717 (to CT).

\section{REFERENCES}

1. O’Rourke MF, Mancia G. Arterial stiffness. J Hypertens. (1999) 17:1065-72. doi: 10.1097/00004872-199917010-00001

2. Laurent S, Cockcroft J, Van Bortel L, Boutouyrie P, Giannattasio C, Hayoz D, et al. Expert consensus document on arterial stiffness: methodological issues and clinical applications. Eur Heart J. (2006) 27:2588605. doi: 10.1093/eurheartj/ehl254

3. Kaess BM, Rong J, Larson MG, Hamburg NM, Vita JA, Levy D, et al. Aortic stiffness, blood pressure progression, incident hypertension. JAMA. (2012) 308:875-81. doi: 10.1001/2012.jama.10503

4. van Popele NM, Grobbee DE, Bots ML, Asmar R, Topouchian J, Reneman RS, et al. Association between arterial stiffness and atherosclerosis: the rotterdam study. Stroke. (2001) 32:454-60. doi: 10.1161/01.STR.32.2.454

5. Baumann M, Wassertheurer S, Suttmann Y, Burkhardt K, Heemann U. Aortic pulse wave velocity predicts mortality in chronic kidney disease stages 2-4. J Hypertens. (2014) 32:899-903. doi: 10.1097/HJH.0000000000000113

6. Feistritzer HJ, Klug G, Reinstadler SJ, Reindl M, Niess L, Nalbach $\mathrm{T}$, et al. prognostic value of aortic stiffness in patients after stelevation myocardial infarction. J Am Heart Assoc. (2017) 6:e005590. doi: 10.1161/JAHA.117.005590

7. Laurent S, Boutouyrie P, Asmar R, Gautier I, Laloux B, Guize L, et al. Aortic stiffness is an independent predictor of all-cause and cardiovascular mortality in hypertensive patients. Hypertension. (2001) 37:1236-41. doi: 10.1161/01.HYP.37.5.1236

8. Mitchell GF, Hwang SJ, Vasan RS, Larson MG, Pencina MJ, Hamburg NM, et al. Arterial stiffness and cardiovascular events: the framingham heart study. Circulation. (2010) 121:505-11. doi: 10.1161/CIRCULATIONAHA.109.886655

9. Mattace-Raso FU, van der Cammen TJ, Hofman A, van Popele NM, Bos ML, Schalekamp MA, et al. Arterial stiffness and risk of coronary heart disease and stroke: the rotterdam study. Circulation. (2006) 113:657-63. doi: 10.1161/CIRCULATIONAHA.105.555235

10. Sutton-Tyrrell K, Najjar SS, Boudreau RM, Venkitachalam L, Kupelian V, Simonsick EM, et al. Elevated aortic pulse wave velocity, a marker of arterial stiffness, predicts cardiovascular events in well-functioning older adults. Circulation. (2005) 111:3384-90. doi: 10.1161/CIRCULATIONAHA.104.483628

11. Willum-Hansen T, Staessen JA, Torp-Pedersen C, Rasmussen S, Thijs L, Ibsen $\mathrm{H}$, et al. Prognostic value of aortic pulse wave velocity as index of arterial stiffness in the general population. Circulation. (2006) 113:664-70. doi: 10.1161/CIRCULATIONAHA.105.579342

12. Sarafidis PA, Loutradis C, Karpetas A, Tzanis G, Piperidou A, Koutroumpas $\mathrm{G}$, et al. Ambulatory pulse wave velocity is a stronger predictor of cardiovascular events and all-cause mortality than office and ambulatory blood pressure in hemodialysis patients. Hypertension. (2017) 70:148-57. doi: 10.1161/HYPERTENSIONAHA.117.09023

13. Vlachopoulos C, Aznaouridis K, Stefanadis C. Prediction of cardiovascular events and all-cause mortality with arterial stiffness: a systematic review and meta-analysis. J Am Coll Cardiol. (2010) 55:1318-27. doi: 10.1016/j.jacc.2009.10.061

14. Ben-Shlomo Y, Spears M, Boustred C, May M, Anderson SG, Benjamin EJ, et al. Aortic pulse wave velocity improves cardiovascular event prediction: an individual participant meta-analysis of prospective observational data from 17,635 subjects. J Am Coll Cardiol. (2014) 63:636-46. doi: 10.1016/j.jacc.2013.09.063

15. Townsend RR, Wilkinson IB, Schiffrin EL, Avolio AP, Chirinos JA, Cockcroft JR, et al. Recommendations for improving and standardizing vascular research on arterial stiffness: a scientific statement from

\section{ACKNOWLEDGMENTS}

We would like to thank Matthew Borinshteyn for his assistance in drafting the tables.

the American heart association. Hypertension. (2015) 66:698-722. doi: 10.1161/HYP.0000000000000033

16. Calabia J, Torguet P, Garcia M, Garcia I, Martin N, Guasch B, et al. Doppler ultrasound in the measurement of pulse wave velocity: agreement with the complior method. Cardiovasc Ultrasound. (2011) 9:13. doi: 10.1186/1476-7120-9-13

17. Jiang B, Liu B, McNeill KL, Chowienczyk PJ. Measurement of pulse wave velocity using pulse wave doppler ultrasound: comparison with arterial tonometry. Ultrasound Med Biol. (2008) 34:509-12. doi: 10.1016/j.ultrasmedbio.2007.09.008

18. Hickson SS, Butlin M, Broad J, Avolio AP, Wilkinson IB, McEniery CM. Validity and repeatability of the vicorder apparatus: a comparison with the SphygmoCor device. Hypertens Res. (2009) 32:1079-85. doi: 10.1038/hr.2009.154

19. Laurent S, Marais L, Boutouyrie P. The noninvasive assessment of vascular AGING. Can J Cardiol. (2016) 32:669-79. doi: 10.1016/j.cjca.2016.01.039

20. Wilkinson IB, Mäki-Petäjä KM, Mitchell GF. Uses of arterial stiffness in clinical practice. Arterioscler Thromb Vasc Biol. (2020) 40:1063-7. doi: 10.1161/ATVBAHA.120.313130

21. Jeroncic A, Gunjaca G, Mrsic DB, Mudnic I, Brizic I, Polasek O, et al. Normative equations for central augmentation index: assessment of interpopulation applicability and how it could be improved. Sci Rep. (2016) 6:27016. doi: 10.1038/srep27016

22. Kim EJ, Park CG, Park JS, Suh SY, Choi CU, Kim JW, et al. Relationship between blood pressure parameters and pulse wave velocity in normotensive and hypertensive subjects: invasive study. J Hum Hypertens. (2007) 21:141-8. doi: 10.1038/sj.jhh.1002120

23. Van Bortel LM, Laurent S, Boutouyrie P, Chowienczyk P, Cruickshank JK, De Backer T, et al. Expert consensus document on the measurement of aortic stiffness in daily practice using carotid-femoral pulse wave velocity. J Hypertens. (2012) 30:445-8. doi: 10.1097/HJH.0b013e32834 fa 8 b0

24. Cavalcante JL, Lima JA, Redheuil A, Al-Mallah MH. Aortic stiffness: current understanding and future directions. J Am Coll Cardiol. (2011) 57:1511-22. doi: 10.1016/j.jacc.2010.12.017

25. Hashimoto J, Imai Y, O'Rourke MF. Indices of pulse wave analysis are better predictors of left ventricular mass reduction than cuff pressure. Am J Hypertens. (2007) 20:378-84. doi: 10.1016/j.amjhyper.2006. 09.019

26. Weber T, Auer J, O’Rourke M F, Kvas E, Lassnig E, Lamm G, et al. Increased arterial wave reflections predict severe cardiovascular events in patients undergoing percutaneous coronary interventions. Eur Heart J. (2005) 26:2657-63. doi: 10.1093/eurheartj/ehi504

27. Chun $\mathrm{KH}$, Lee CJ, Oh J, Won C, Lee T, Park S, et al. Increased aortic augmentation index is associated with reduced exercise capacity after heart transplantation. J Hypertens. (2020) 38:1777-85. doi: 10.1097/HJH.0000000000002455

28. Sakurai M, Yamakado T, Kurachi H, Kato T, Kuroda K, Ishisu $\mathrm{R}$, et al. The relationship between aortic augmentation index and pulse wave velocity: an invasive study. J Hypertens. (2007) 25:391-7. doi: 10.1097/HJH.0b013e3280115b7c

29. Yasmin, Brown MJ. Similarities and differences between augmentation index and pulse wave velocity in the assessment of arterial stiffness. QJM. (1999) 92:595-600. doi: 10.1093/qjmed/92.10.595

30. Mancia G, De Backer G, Dominiczak A, Cifkova R, Fagard R, Germano G, et al. 2007 guidelines for the management of arterial hypertension: the task force for the management of arterial hypertension of the European society of hypertension (ESH) and of the European society of cardiology (ESC). $J$ Hypertens. (2007) 25:1105-87. doi: 10.1097/HJH.0b013e3281fc975a 
31. Reference Values for Arterial Stiffness Collaboration. Determinants of pulse wave velocity in healthy people and in the presence of cardiovascular risk factors: 'establishing normal and reference values'. Eur Heart J. (2010) 31:2338-50. doi: 10.1093/eurheartj/ehq165

32. Rajzer MW, Wojciechowska W, Klocek M, Palka I, Brzozowska-Kiszka M, Kawecka-Jaszcz K. Comparison of aortic pulse wave velocity measured by three techniques: complior, SphygmoCor and arteriograph. J Hypertens. (2008) 26:2001-7. doi: 10.1097/HJH.0b013e32830a4a25

33. Khoshdel AR, Thakkinstian A, Carney SL, Attia J. Estimation of an age-specific reference interval for pulse wave velocity: a meta-analysis. $J$ Hypertens. (2006) 24:1231-7. doi: 10.1097/01.hjh.0000234098.85497.31

34. Mitchell GF, Parise H, Benjamin EJ, Larson MG, Keyes MJ, Vita JA, et al. Changes in arterial stiffness and wave reflection with advancing age in healthy men and women: the framingham heart study. Hypertension. (2004) 43:1239-45. doi: 10.1161/01.HYP.0000128420.01881.aa

35. Tsao CW, Washington F, Musani SK, Cooper LL, Tripathi A, Hamburg $\mathrm{NM}$, et al. Clinical correlates of aortic stiffness and wave amplitude in black men and women in the community. J Am Heart Assoc. (2018) 7:e008431. doi: 10.1161/JAHA.117.008431

36. Franklin SS, Gustin Wt, Wong ND, Larson MG, Weber MA, Kannel $\mathrm{WB}$, et al. Hemodynamic patterns of age-related changes in blood pressure. The framingham heart study. Circulation. (1997) 96:308-15. doi: 10.1161/01.CIR.96.1.308

37. Saba PS, Roman MJ, Pini R, Spitzer M, Ganau A, Devereux RB. Relation of arterial pressure waveform to left ventricular and carotid anatomy in normotensive subjects. J Am Coll Cardiol. (1993) 22:1873-80. doi: 10.1016/0735-1097(93)90772-S

38. Cruickshank JM. The role of coronary perfusion pressure. Euro Heart J. (1992) 13:39-43. doi: 10.1093/eurheartj/13.suppl_D.39

39. Madhuri V, Chandra S, Jabbar A. Age associated increase in intima media thickness in adults. Indian J Physiol Pharmacol. (2010) 54:371-5.

40. Lakatta EG, Levy D. Arterial and cardiac aging: major shareholders in cardiovascular disease enterprises. Circulation. (2003) 107:139-46. doi: 10.1161/01.CIR.0000048892.83521.58

41. Tsao CW, Pencina KM, Massaro JM, Benjamin EJ, Levy D, Vasan RS, et al. Cross-sectional relations of arterial stiffness, pressure pulsatility, wave reflection, arterial calcification. Arterioscler Thromb Vasc Biol. (2014) 34:2495-500. doi: 10.1161/ATVBAHA.114.303916

42. Loboz-Rudnicka M, Jaroch J, Bociaga Z, Kruszynska E, Ciecierzynska $B$, Dziuba $M$, et al. Relationship between vascular age and classic cardiovascular risk factors and arterial stiffness. Cardiol J. (2013) 20:394-401. doi: 10.5603/CJ.2013.0098

43. Rossi P, Francès Y, Kingwell BA, Ahimastos AA. Gender differences in artery wall biomechanical properties throughout life. J Hypertens. (2011) 29:1023-33. doi: 10.1097/HJH.0b013e328344da5e

44. Tomiyama H, Yamashina A, Arai T, Hirose K, Koji Y, Chikamori T, et al. Influences of age and gender on results of noninvasive brachial-ankle pulse wave velocity measurement-a survey of 12517 subjects. Atherosclerosis. (2003) 166:303-9. doi: 10.1016/S0021-9150(02)00332-5

45. Protogerou AD, Blacher J, Aslangul E, Le Jeunne C, Lekakis J, Mavrikakis $\mathrm{M}$, et al. Gender influence on metabolic syndrome's effects on arterial stiffness and pressure wave reflections in treated hypertensive subjects. Atherosclerosis. (2007) 193:151-8. doi: 10.1016/j.atherosclerosis.2006.05.046

46. Yaron M, Greenman Y, Rosenfeld JB, Izkhakov E, Limor R, Osher E, et al. Effect of testosterone replacement therapy on arterial stiffness in older hypogonadal men. Eur J Endocrinol. (2009) 160:839-46. doi: 10.1530/EJE-09-0052

47. Yue P, Chatterjee K, Beale C, Poole-Wilson PA, Collins P. Testosterone relaxes rabbit coronary arteries and aorta. Circulation. (1995) 91:1154-60. doi: 10.1161/01.CIR.91.4.1154

48. Pfeilschifter J, Köditz R, Pfohl M, Schatz H. Changes in proinflammatory cytokine activity after menopause. Endocr Rev. (2002) 23:90-119. doi: 10.1210/edrv.23.1.0456

49. Natoli AK, Medley TL, Ahimastos AA, Drew BG, Thearle DJ, Dilley RJ, et al. Sex steroids modulate human aortic smooth muscle cell matrix protein deposition and matrix metalloproteinase expression. Hypertension. (2005) 46:1129-34. doi: 10.1161/01.HYP.0000187016.06549.96
50. Muntner P, Lewis CE, Diaz KM, Carson AP, Kim Y, Calhoun D, et al. Racial differences in abnormal ambulatory blood pressure monitoring measures: results from the coronary artery risk development in young adults (CARDIA) study. Am J Hypertens. (2015) 28:640-8. doi: 10.1093/ajh/hpu193

51. Heffernan KS, Jae SY, Wilund KR, Woods JA, Fernhall B. Racial differences in central blood pressure and vascular function in young men. Am J Physiol Heart Circul Physiol. (2008) 295:H2380-7. doi: 10.1152/ajpheart.00902.2008

52. Hozawa A, Folsom AR, Sharrett AR, Chambless LE. Absolute and attributable risks of cardiovascular disease incidence in relation to optimal and borderline risk factors: comparison of African American with white subjects-atherosclerosis risk in communities study. Arch Intern Med. (2007) 167:573-9. doi: 10.1001/archinte.167.6.573

53. Din-Dzietham R, Couper D, Evans G, Arnett DK, Jones DW. Arterial stiffness is greater in African Americans than in whites: evidence from the forsyth county, north carolina, ARIC cohort. Am J Hypertens. (2004) 17:304-13. doi: 10.1016/j.amjhyper.2003.12.004

54. Mokwatsi GG, Schutte AE, Kruger R. Ethnic differences regarding arterial stiffness of 6-8-year-old black and white boys. J Hypertens. (2017) 35:960-7. doi: 10.1097/HJH.0000000000001267

55. Thurston RC, Matthews KA. Racial and socioeconomic disparities in arterial stiffness and intima media thickness among adolescents. Soc Sci Med. (2009) 68:807-13. doi: 10.1016/j.socscimed.2008.12.029

56. Lefferts WK, Augustine JA, Spartano NL, Atallah-Yunes NH, Heffernan KS, Gump BB. Racial differences in aortic stiffness in children. J Pediatr. (2017) 180:62-7. doi: 10.1016/j.jpeds.2016.09.071

57. Malayeri AA, Natori S, Bahrami H, Bertoni AG, Kronmal R, Lima JA, et al. Relation of aortic wall thickness and distensibility to cardiovascular risk factors [from the multi-ethnic study of atherosclerosis (MESA)]. Am J Cardiol. (2008) 102:491-6. doi: 10.1016/j.amjcard.2008.04.010

58. Goel A, Maroules CD, Mitchell GF, Peshock R, Ayers C, McColl R, et al. Ethnic difference in proximal aortic stiffness: an observation from the dallas heart study. JACC Cardiovasc Imaging. (2017) 10:54-61. doi: 10.1016/j.jcmg.2016.07.012

59. Baldo MP, Cunha RS, Ribeiro ALP, Lotufo PA, Chor D, Barreto SM, et al. Racial differences in arterial stiffness are mainly determined by blood pressure levels: results from the ELSA-Brasil study. J Am Heart Assoc. (2017) 6:e005477. doi: 10.1161/JAHA.117.005477

60. Birru MS, Matthews KA, Thurston RC, Brooks MM, Ibrahim S, BarinasMitchell E, et al. African-American ethnicity and cardiovascular risk factors are related to aortic pulse-wave velocity progression. Am J Hypertens. (2011) 24:809-15. doi: 10.1038/ajh.2011.57

61. Dong Y, Pollock N, Stallmann-Jorgensen IS, Gutin B, Lan L, Chen TC, et al. Low 25-hydroxyvitamin D levels in adolescents: race, season, adiposity, physical activity, and fitness. Pediatrics. (2010) 125:1104-11. doi: 10.1542/peds.2009-2055

62. Raed A, Bhagatwala J, Zhu H, Pollock NK, Parikh SJ, Huang Y, et al. Dose responses of vitamin D3 supplementation on arterial stiffness in overweight African Americans with vitamin D deficiency: a placebo controlled randomized trial. PLOS ONE. (2017) 12:e0188424. doi: 10.1371/journal.pone.0188424

63. Kalinowski L, Dobrucki IT, Malinski T. Race-specific differences in endothelial function: predisposition of African Americans to vascular diseases. Circulation. (2004) 109:2511-7. doi: 10.1161/01.CIR.0000129087.81352.7A

64. Campia U, Choucair WK, Bryant MB, Waclawiw MA, Cardillo C, Panza JA. Reduced endothelium-dependent and -independent dilation of conductance arteries in African Americans. J Am Coll Cardiol. (2002) 40:754-60. doi: 10.1016/S0735-1097(02)02015-6

65. Morris AA, Patel RS, Binongo JN, Poole J, Al Mheid I, Ahmed Y, et al. Racial differences in arterial stiffness and microcirculatory function between black and white Americans. J Am Heart Assoc. (2013) 2:e002154 doi: 10.1161/JAHA.112.002154

66. McEniery CM, Spratt M, Munnery M, Yarnell J, Lowe GD, Rumley A, et al. An analysis of prospective risk factors for aortic stiffness in men: 20-year follow-up from the caerphilly prospective study. Hypertension. (2010) 56:36-43. doi: 10.1161/HYPERTENSIONAHA.110. 150896 
67. Zieman SJ, Melenovsky V, Kass DA. Mechanisms, pathophysiology, and therapy of arterial stiffness. Arterioscler Thromb Vasc Biol. (2005) 25:932-43. doi: 10.1161/01.ATV.0000160548.78317.29

68. Tedla YG, Yano Y, Carnethon M, Greenland P. Association between longterm blood pressure variability and 10-year progression in arterial stiffness: the multiethnic study of atherosclerosis. Hypertension. (2017) 69:118-27. doi: 10.1161/HYPERTENSIONAHA.116.08427

69. Aoki Y, Kai H, Kajimoto H, Kudo H, Takayama N, Yasuoka S, et al. Large blood pressure variability aggravates arteriolosclerosis and cortical sclerotic changes in the kidney in hypertensive rats. Circ J. (2014) 78:2284-91. doi: 10.1253/circj.CJ-14-0027

70. Chappell DC, Varner SE, Nerem RM, Medford RM, Alexander RW. Oscillatory shear stress stimulates adhesion molecule expression in cultured human endothelium. Circ Res. (1998) 82:532-9. doi: 10.1161/01.RES.82.5.532

71. Shimbo D, Shea S, McClelland RL, Viera AJ, Mann D, Newman $\mathrm{J}$, et al. Associations of aortic distensibility and arterial elasticity with long-term visit-to-visit blood pressure variability: the multi-ethnic study of atherosclerosis (MESA). Am J Hypertens. (2013) 26:896-902. doi: 10.1093/ajh/hpt040

72. Dernellis J, Panaretou M. Aortic stiffness is an independent predictor of progression to hypertension in nonhypertensive subjects. Hypertension. (2005) 45:426-31. doi: 10.1161/01.HYP.0000157818.58878.93

73. Franklin SS. Arterial stiffness and hypertension: a two-way street? Hypertension. (2005) 45:349-51. doi: 10.1161/01.HYP.0000157819.31611.87

74. Mitchell GF. Arterial stiffness and hypertension: chicken or egg? Hypertension. (2014) 64:210-4. doi: 10.1161/HYPERTENSIONAHA.114.03449

75. Najjar SS, Scuteri A, Shetty V, Wright JG, Muller DC, Fleg JL, et al. Pulse wave velocity is an independent predictor of the longitudinal increase in systolic blood pressure and of incident hypertension in the Baltimore longitudinal study of aging. J Am Coll Cardiol. (2008) 51:1377-83. doi: 10.1016/j.jacc.2007.10.065

76. Weisbrod RM, Shiang T, Al Sayah L, Fry JL, Bajpai S, ReinhartKing CA, et al. Arterial stiffening precedes systolic hypertension in diet-induced obesity. Hypertension. (2013) 62:1105-10. doi: 10.1161/HYPERTENSIONAHA.113.01744

77. Li S, Chen W, Srinivasan SR, Berenson GS. Influence of metabolic syndrome on arterial stiffness and its age-related change in young adults: the bogalusa heart study. Atherosclerosis. (2005) 180:349-54. doi: 10.1016/j.atherosclerosis.2004.12.016

78. Gomez-Sanchez L, Garcia-Ortiz L, Patino-Alonso MC, Recio-Rodriguez JI, Fernando R, Marti R, et al. Association of metabolic syndrome and its components with arterial stiffness in caucasian subjects of the MARK study: a cross-sectional trial. Cardiovasc Diabetol. (2016) 15:148. doi: 10.1186/s12933-016-0465-7

79. Safar ME, Thomas F, Blacher J, Nzietchueng R, Bureau JM, Pannier B, et al. Metabolic syndrome and age-related progression of aortic stiffness. J Am Coll Cardiol. (2006) 47:72-5. doi: 10.1016/j.jacc.2005.08.052

80. Terentes-Printzios D, Vlachopoulos C, Xaplanteris P, Ioakeimidis $\mathrm{N}$, Aznaouridis $\mathrm{K}$, Baou $\mathrm{K}$, et al. Cardiovascular risk factors accelerate progression of vascular aging in the general population: results from the CRAVE Study (cardiovascular risk factors affecting vascular age). Hypertension. (2017) 70:1057-64. doi: 10.1161/HYPERTENSIONAHA.117.09633

81. Tomiyama H, Hirayama Y, Hashimoto H, Yambe M, Yamada J, Koji Y, et al. The effects of changes in the metabolic syndrome detection status on arterial stiffening: a prospective study. Hypertens Res. (2006) 29:673-8. doi: 10.1291/hypres.29.673

82. Haffner SM, Lehto S, Ronnemaa T, Pyorala K, Laakso M. Mortality from coronary heart disease in subjects with type 2 diabetes and in nondiabetic subjects with and without prior myocardial infarction. N Engl J Med. (1998) 339:229-34. doi: 10.1056/NEJM199807233390404

83. Kannel WB, McGee DL. Diabetes and glucose tolerance as risk factors for cardiovascular disease: the framingham study. Diabetes Care. (1979) 2:120-6. doi: $10.2337 /$ diacare.2.2.120

84. Mansour AS, Yannoutsos A, Majahalme N, Agnoletti D, Safar ME, Ouerdane $S$, et al. Aortic stiffness and cardiovascular risk in type 2 diabetes. J Hypertens. (2013) 31:1584-92. doi: 10.1097/HJH.0b013e32836 13074

85. Pietri P, Vlachopoulos C, Vyssoulis G, Ioakeimidis N, Stefanadis C. Macro- and microvascular alterations in patients with metabolic syndrome: sugar makes the difference. Hypertens Res. (2014) 37:452-6. doi: 10.1038/hr.2013.148

86. Di Pino A, Currenti W, Urbano F, Scicali R, Piro S, Purrello F, et al. High intake of dietary advanced glycation end-products is associated with increased arterial stiffness and inflammation in subjects with type 2 diabetes. Nutr Metab Cardiovasc Dis. (2017) 27:978-84. doi: 10.1016/j.numecd.2017.06.014

87. Kass DA, Shapiro EP, Kawaguchi M, Capriotti AR, Scuteri A, deGroof $\mathrm{RC}$, et al. Improved arterial compliance by a novel advanced glycation end-product crosslink breaker. Circulation. (2001) 104:1464-70. doi: 10.1161/hc3801.097806

88. Engelen L, Ferreira I, Gaens KH, Henry RM, Dekker JM, Nijpels G, et al. The association between the-374T/A polymorphism of the receptor for advanced glycation endproducts gene and blood pressure and arterial stiffness is modified by glucose metabolism status: the hoorn and CoDAM studies. J Hypertens. (2010) 28:285-93. doi: 10.1097/HJH.0b013e3283 330931

89. Lastra-Lastra G, Sowers JR, Restrepo-Erazo K, Manrique-Acevedo C, Lastra-Gonzalez G. Role of aldosterone and angiotensin II in insulin resistance: an update. Clin Endocrinol. (2009) 71:1-6. doi: 10.1111/j.1365-2265.2008.03498.x

90. Elliott P, Stamler J, Nichols R, Dyer AR, Stamler R, Kesteloot H, et al. Intersalt revisited: further analyses of 24 hour sodium excretion and blood pressure within and across populations. Intersalt cooperative research group. BMJ. (1996) 312:1249-53. doi: 10.1136/bmj.312.7041.1249

91. Jablonski KL, Fedorova OV, Racine ML, Geolfos CJ, Gates PE, Chonchol $\mathrm{M}$, et al. Dietary sodium restriction and association with urinary marinobufagenin, blood pressure, aortic stiffness. Clin J Am Soc Nephrol. (2013) 8:1952-9. doi: 10.2215/CJN.00900113

92. Vaitkevicius PV, Fleg JL, Engel JH, O'Connor FC, Wright JG, Lakatta LE, et al. Effects of age and aerobic capacity on arterial stiffness in healthy adults. Circulation. (1993) 88:1456-62. doi: 10.1161/01.CIR.88.4.1456

93. Tanaka H, DeSouza CA, Seals DR. Absence of age-related increase in central arterial stiffness in physically active women. Arterioscler Thromb Vasc Biol. (1998) 18:127-32. doi: 10.1161/01.ATV.18.1.127

94. Lopes S, Afreixo V, Teixeira M, Garcia C, Leitão C, Gouveia M, et al. Exercise training reduces arterial stiffness in adults with hypertension: a systematic review and meta-analysis. J Hypertens. (2021) 39:214-22. doi: 10.1097/HJH.0000000000002619

95. Lekakis J, Papamichael C, Vemmos C, Nanas J, Kontoyannis D, Stamatelopoulos S, et al. Effect of acute cigarette smoking on endotheliumdependent brachial artery dilatation in healthy individuals. Am J Cardiol. (1997) 79:529-31. doi: 10.1016/S0002-9149(96)00805-3

96. Celermajer DS, Sorensen KE, Georgakopoulos D, Bull C, Thomas O, Robinson J, et al. Cigarette smoking is associated with dose-related and potentially reversible impairment of endothelium-dependent dilation in healthy young adults. Circulation. (1993) 88:2149-55. doi: 10.1161/01.CIR.88.5.2149

97. Lee GB, Shim JS, Kim HC. Dose-response association between smoking cessation and arterial stiffness: the cardiovascular and metabolic diseases etiology research center (CMERC) cohort. Korean Circ J. (2020) 50:361-9. doi: $10.4070 / \mathrm{kcj} .2019 .0270$

98. Vlachopoulos C, Ioakeimidis N, Abdelrasoul M, Terentes-Printzios D, Georgakopoulos C, Pietri P, et al. Electronic cigarette smoking increases aortic stiffness and blood pressure in young smokers. J Am Coll Cardiol. (2016) 67:2802-3. doi: 10.1016/j.jacc.2016.03.569

99. Sierksma A, Muller M, van der Schouw YT, Grobbee DE, Hendriks HF, Bots ML. Alcohol consumption and arterial stiffness in men. J Hypertens. (2004) 22:357-62. doi: 10.1097/00004872-200402000-00020

100. Sierksma A, Lebrun CE, van der Schouw YT, Grobbee DE, Lamberts SW, Hendriks HF, et al. Alcohol consumption in relation to aortic stiffness and aortic wave reflections: a cross-sectional study in healthy postmenopausal women. Arterioscler Thromb Vasc Biol. (2004) 24:342-8. doi: 10.1161/01.ATV.0000110784.52412.8f 
101. Yu A, Cooke AB, Scheffler P, Doonan RJ, Daskalopoulou SS. Alcohol exerts a shifted u-shaped effect on central blood pressure in young adults. J Gen Intern Med. (2021) 36:2975-81. doi: 10.1007/s11606-021-06665-0

102. Nishiwaki M, Kora N, Matsumoto N. Ingesting a small amount of beer reduces arterial stiffness in healthy humans. Physiol Rep. (2017) 5:e13381. doi: 10.14814 /phy2.13381

103. Gardner JD, Mouton AJ. Alcohol effects on cardiac function. Compr Physiol. (2015) 5:791-802. doi: 10.1002/cphy.c140046

104. Kuhlmann CR, Li F, Lüdders DW, Schaefer CA, Most AK, Backenköhler U, et al. Dose-dependent activation of $\mathrm{Ca} 2+$-activated $\mathrm{K}+$ channels by ethanol contributes to improved endothelial cell functions. Alcohol Clin Exp Res. (2004) 28:1005-11. doi: 10.1097/01.ALC.0000130811.92457.0D

105. Centers for Disease Control and Prevention. Cigarette smoking among adults-United States, 2000. MMWMorb Rep. (2002) 51:642-5.

106. Mahmud A, Feely J. Effect of smoking on arterial stiffness and pulse pressure amplification. Hypertension. (2003) 41:183-7. doi: 10.1161/01.HYP.0000047464.66901.60

107. Stefanadis C, Vlachopoulos C, Tsiamis E, Diamantopoulos L, Toutouzas $\mathrm{K}$, Giatrakos $\mathrm{N}$, et al. Unfavorable effects of passive smoking on aortic function in men. Ann Intern Med. (1998) 128:426-34. doi: 10.7326/0003-4819-128-6-199803150-00002

108. Jatoi NA, Jerrard-Dunne $P$, Feely J, Mahmud A. Impact of smoking and smoking cessation on arterial stiffness and aortic wave reflection in hypertension. Hypertension. (2007) 49:981-5. doi: 10.1161/HYPERTENSIONAHA.107.087338

109. Doonan RJ, Hausvater A, Scallan C, Mikhailidis DP, Pilote L, Daskalopoulou SS. The effect of smoking on arterial stiffness. Hypertens Res. (2010) 33:398410. doi: 10.1038/hr.2010.25

110. Tanaka H, Safar ME. Influence of lifestyle modification on arterial stiffness and wave reflections. Am J Hypertens. (2005) 18:137-44. doi: 10.1016/j.amjhyper.2004.07.008

111. He FJ, Li J, Macgregor GA. Effect of longer term modest salt reduction on blood pressure: Cochrane systematic review and meta-analysis of randomised trials. BMJ. (2013) 346:f1325. doi: 10.1136/bmj.f1325

112. Avolio AP, Clyde KM, Beard TC, Cooke HM, Ho KK, O’Rourke MF. Improved arterial distensibility in normotensive subjects on a low salt diet. Arteriosclerosis. (1986) 6:166-9. doi: 10.1161/01.ATV.6.2.166

113. Livingstone KM, Givens DI, Cockcroft JR, Pickering JE, Lovegrove JA. Is fatty acid intake a predictor of arterial stiffness and blood pressure in men? Evidence from the caerphilly prospective study. Nutr Metab Cardiovasc Dis. (2013) 23:1079-85. doi: 10.1016/j.numecd.2012.12.002

114. Crichton GE, Elias MF, Dore GA, Abhayaratna WP, Robbins MA. Relations between dairy food intake and arterial stiffness: pulse wave velocity and pulse pressure. Hypertension. (2012) 59:1044-51. doi: 10.1161/HYPERTENSIONAHA.111.190017

115. Petersen KS, Keogh JB, Meikle PJ, Garg ML, Clifton PM. Dietary predictors of arterial stiffness in a cohort with type 1 and type 2 diabetes. Atherosclerosis. (2015) 238:175-81. doi: 10.1016/j.atherosclerosis.2014.12.012

116. Aatola $\mathrm{H}$, Koivistoinen $\mathrm{T}$, Hutri-Kähönen $\mathrm{N}$, Juonala $\mathrm{M}$, Mikkilä $\mathrm{V}$, Lehtimäki $\mathrm{T}$, et al. Lifetime fruit and vegetable consumption and arterial pulse wave velocity in adulthood: the cardiovascular risk in young finns study. Circulation. (2010) 122:2521-8. doi: 10.1161/CIRCULATIONAHA.110.969279

117. Green D, Cheetham C, Mavaddat L, Watts K, Best M, Taylor R, et al. Effect of lower limb exercise on forearm vascular function: contribution of nitric oxide. Am J Physiol Heart Circul Physiol. (2002) 283:H899-907. doi: 10.1152/ajpheart.00049.2002

118. Green DJ, Bilsborough W, Naylor LH, Reed C, Wright J, O’Driscoll G, et al. Comparison of forearm blood flow responses to incremental handgrip and cycle ergometer exercise: relative contribution of nitric oxide. J Physiol. (2005) 562:617-28. doi: 10.1113/jphysiol.2004.075929

119. Sacre K, Escoubet B, Pasquet B, Chauveheid MP, Zennaro MC, Tubach $F$, et al. Increased arterial stiffness in systemic lupus erythematosus (SLE) patients at low risk for cardiovascular disease: a cross-sectional controlled study. PLoS ONE. (2014) 9:e94511. doi: 10.1371/journal.pone.0094511

120. Zanoli L, Boutouyrie P, Fatuzzo P, Granata A, Lentini P, Ozturk K, et al. Inflammation and aortic stiffness: an individual participant data meta-analysis in patients with inflammatory bowel disease. J Am Heart Assoc. (2017) 6. doi: 10.1161/JAHA.117.007003

121. Anyfanti P, Triantafyllou A, Gkaliagkousi E, Koletsos N, Aslanidis S, Douma S. Association of non-invasive hemodynamics with arterial stiffness in rheumatoid arthritis. Scand Cardiovasc J. (2018) 52:171-6. doi: 10.1080/14017431.2018.1453943

122. Maloberti A, Riva M, Tadic M, Valena C, Villa P, Boggioni I, et al. Association between atrial, ventricular and vascular morphofunctional alterations in rheumatoid arthritis. High Blood Press Cardiovasc Prev. (2018) 25:97-104. doi: 10.1007/s40292-017-0246-8

123. Costa L, Caso F, D'Elia L, Atteno M, Peluso R, Del Puente A, et al. Psoriatic arthritis is associated with increased arterial stiffness in the absence of known cardiovascular risk factors: a case control study. Clin Rheumatol. (2012) 31:711-5. doi: 10.1007/s10067-011-1892-1

124. Shen J, Shang Q, Li EK, Leung YY, Kun EW, Kwok LW, et al. Cumulative inflammatory burden is independently associated with increased arterial stiffness in patients with psoriatic arthritis: a prospective study. Arthritis Res Ther. (2015) 17:75. doi: 10.1186/s13075-015-0570-0

125. Sezis Demirci M, Karabulut G, Gungor O, Celtik A, Ok E, Kabasakal Y. Is there an increased arterial stiffness in patients with primary sjögren's syndrome? Intern Med. (2016) 55:455-9. doi: 10.2169/internalmedicine.55.3472

126. Ozisler C, Kaplanoglu H. Evaluation of subclinical atherosclerosis by ultrasound radiofrequency data technology in patients with primary Sjögren's syndrome. Clin Rheumatol. (2019) 38:709-17. doi: 10.1007/s10067-018-4330-9

127. Roman MJ, Devereux RB, Schwartz JE, Lockshin MD, Paget SA, Davis A, et al. Arterial stiffness in chronic inflammatory diseases. Hypertension. (2005) 46:194-9. doi: 10.1161/01.HYP.0000168055.89955.db

128. Tomiyama H, Shiina K, Matsumoto-Nakano C, Ninomiya T, Komatsu S, Kimura K, et al. The contribution of inflammation to the development of hypertension mediated by increased arterial stiffness. J Am Heart Assoc. (2017) 6:e05729. doi: 10.1161/JAHA.117.005729

129. Mattace-Raso FU, van der Cammen TJ, van der Meer IM, Schalekamp MA, Asmar R, Hofman A, et al. C-reactive protein and arterial stiffness in older adults: the rotterdam study. Atherosclerosis. (2004) 176:111-6. doi: 10.1016/j.atherosclerosis.2004.04.014

130. Fichtlscherer S, Rosenberger G, Walter DH, Breuer S, Dimmeler S, Zeiher AM. Elevated C-reactive protein levels and impaired endothelial vasoreactivity in patients with coronary artery disease. Circulation. (2000) 102:1000-6. doi: 10.1161/01.CIR.102.9.1000

131. Mahmud A, Feely J. Arterial stiffness is related to systemic inflammation in essential hypertension. Hypertension. (2005) 46:1118-22. doi: 10.1161/01.HYP.0000185463.27209.b0

132. Sie MP, Mattace-Raso FU, Uitterlinden AG, Arp PP, Hofman A, Pols HA, et al. The interleukin-6-174 G/C promoter polymorphism and arterial stiffness; the rotterdam study. Vasc Health Risk Manag. (2008) 4:863-9. doi: 10.2147/VHRM.S1693

133. Vlachopoulos C, Gravos A, Georgiopoulos G, Terentes-Printzios D, Ioakeimidis N, Vassilopoulos D, et al. The effect of TNF-a antagonists on aortic stiffness and wave reflections: a meta-analysis. Clin Rheumatol. (2018) 37:515-26. doi: 10.1007/s10067-017-3657-y

134. Ikdahl E, Rollefstad S, Hisdal J, Olsen IC, Pedersen TR, Kvien TK, et al. Sustained Improvement of arterial stiffness and blood pressure after long-term rosuvastatin treatment in patients with inflammatory joint diseases: results from the RORA-AS study. PLoS ONE. (2016) 11:e0153440. doi: 10.1371/journal.pone.0153440

135. Wang Y, Sun Z. Current understanding of klotho. Ageing Res Rev. (2009) 8:43-51. doi: 10.1016/j.arr.2008.10.002

136. Chen K, Zhou X, Sun Z. Haplodeficiency of klotho gene causes arterial stiffening via upregulation of scleraxis expression and induction of autophagy. Hypertension. (2015) 66:1006-13. doi: 10.1161/HYPERTENSIONAHA.115.06033

137. Gao D, Zuo Z, Tian J, Ali Q, Lin Y, Lei H, et al. Activation of SIRT1 attenuates klotho deficiency-induced arterial stiffness and hypertension by enhancing AMP-activated protein kinase activity. Hypertension. (2016) 68:1191-9. doi: 10.1161/HYPERTENSIONAHA.116.07709 
138. Kitagawa M, Sugiyama H, Morinaga H, Inoue T, Takiue K, Ogawa A, et al. A decreased level of serum soluble Klotho is an independent biomarker associated with arterial stiffness in patients with chronic kidney disease. PLoS ONE. (2013) 8:e56695. doi: 10.1371/journal.pone.0056695

139. Zarzuelo MJ, Lopez-Sepulveda R, Sanchez M, Romero M, Gomez-Guzman $\mathrm{M}$, Ungvary Z, et al. SIRT1 inhibits NADPH oxidase activation and protects endothelial function in the rat aorta: implications for vascular aging. Biochem Pharmacol. (2013) 85:1288-96. doi: 10.1016/j.bcp.2013.02.015

140. Fry JL, Al Sayah L, Weisbrod RM, Van Roy I, Weng X, Cohen RA, et al. Vascular smooth muscle sirtuin-1 protects against diet-induced aortic stiffness. Hypertension. (2016) 68:775-84. doi: 10.1161/HYPERTENSIONAHA.116.07622

141. Zhou X, Chen K, Wang Y, Schuman M, Lei H, Sun Z. Antiaging gene klotho regulates adrenal CYP11B2 expression and aldosterone synthesis. J Am Soc Nephrol. (2016) 27:1765-76. doi: 10.1681/ASN.2015010093

142. Neves MF, Cunha AR, Cunha MR, Gismondi RA, Oigman W. The role of renin-angiotensin-aldosterone system and its new components in arterial stiffness and vascular aging. High Blood Press Cardiovasc Prev. (2018) 25:13745. doi: 10.1007/s40292-018-0252-5

143. Park S, Kim JB, Shim CY, Ko YG, Choi D, Jang Y, et al. The influence of serum aldosterone and the aldosterone-renin ratio on pulse wave velocity in hypertensive patients. J Hypertens. (2007) 25:1279-83. doi: 10.1097/HJH.0b013e3280f31b6e

144. Benetos A, Topouchian J, Ricard S, Gautier S, Bonnardeaux A, Asmar R, et al. Influence of angiotensin II type 1 receptor polymorphism on aortic stiffness in never-treated hypertensive patients. Hypertension. (1995) 26:447. doi: 10.1161/01.HYP.26.1.44

145. Lajemi M, Labat C, Gautier S, Lacolley P, Safar M, Asmar R, et al. Angiotensin II type 1 receptor-153A/G and 1166A/C gene polymorphisms and increase in aortic stiffness with age in hypertensive subjects. J Hypertens. (2001) 19:407-13. doi: 10.1097/00004872-200103000-00008

146. Dima I, Vlachopoulos C, Alexopoulos N, Baou K, Vasiliadou C, Antoniades $\mathrm{C}$, et al. Association of arterial stiffness with the angiotensin-converting enzyme gene polymorphism in healthy individuals. Am J Hypertens. (2008) 21:1354-8. doi: 10.1038/ajh.2008.295

147. Taniwaki H, Kawagishi T, Emoto M, Shoji T, Hosoi M, Kogawa K, et al. Association of ACE gene polymorphism with arterial stiffness in patients with type 2 diabetes. Diabetes Care. (1999) 22:1858-64. doi: $10.2337 /$ diacare.22.11.1858

148. Pojoga L, Gautier S, Blanc H, Guyene TT, Poirier O, Cambien F, et al. Genetic determination of plasma aldosterone levels in essential hypertension. Am J Hypertens. (1998) 11:856-60. doi: 10.1016/S0895-7061(98) 00048-X

149. Laurent S, Boutouyrie P, Lacolley P. Structural and genetic bases of arterial stiffness. Hypertension. (2005) 45:1050-5. doi: 10.1161/01.HYP.0000164580.39991.3d

150. Nehme JA, Lacolley P, Labat C, Challande P, Robidel E, Perret C, et al. Spironolactone improves carotid artery fibrosis and distensibility in rat post-ischaemic heart failure. J Mol Cell Cardiol. (2005) 39:511-9. doi: 10.1016/j.yjmcc.2005.05.015

151. London GM, Asmar RG, O'Rourke MF, Safar ME. Mechanism(s) of selective systolic blood pressure reduction after a low-dose combination of perindopril/indapamide in hypertensive subjects: comparison with atenolol. J Am Coll Cardiol. (2004) 43:92-9. doi: 10.1016/j.jacc.2003. 07.039

152. Savoia C, Touyz RM, Amiri F, Schiffrin EL. Selective mineralocorticoid receptor blocker eplerenone reduces resistance artery stiffness in hypertensive patients. Hypertension. (2008) 51:432-9. doi: 10.1161/HYPERTENSIONAHA.107.103267

153. Koumaras C, Tziomalos K, Stavrinou E, Katsiki N, Athyros VG, Mikhailidis $\mathrm{DP}$, et al. Effects of renin-angiotensin-aldosterone system inhibitors and beta-blockers on markers of arterial stiffness. J Am Soc Hypertens. (2014) 8:74-82. doi: 10.1016/j.jash.2013.09.001

154. D’Elia L, Galletti F, La Fata E, Sabino P, Strazzullo P. Effect of dietary sodium restriction on arterial stiffness: systematic review and metaanalysis of the randomized controlled trials. J Hypertens. (2018) 36:734-43. doi: 10.1097/HJH.0000000000001604
155. Zeller CB, Appenzeller S. Cardiovascular disease in systemic lupus erythematosus: the role of traditional and lupus related risk factors. Curr Cardiol Rev. (2008) 4:116-22. doi: 10.2174/157340308784245775

156. Yarur AJ, Deshpande AR, Pechman DM, Tamariz L, Abreu MT, Sussman DA. Inflammatory bowel disease is associated with an increased incidence of cardiovascular events. Am J Gastroenterol. (2011) 106:741-7. doi: 10.1038/ajg.2011.63

157. Ahlehoff O, Gislason GH, Charlot M, Jorgensen $\mathrm{CH}$, Lindhardsen J, Olesen JB, et al. Psoriasis is associated with clinically significant cardiovascular risk: a Danish nationwide cohort study. J Intern Med. (2011) 270:147-57. doi: 10.1111/j.1365-2796.2010.02310.x

158. Holloway CJ, Ntusi N, Suttie J, Mahmod M, Wainwright E, Clutton G, et al. Comprehensive cardiac magnetic resonance imaging and spectroscopy reveal a high burden of myocardial disease in HIV patients. Circulation. (2013) 128:814-22. doi: 10.1161/CIRCULATIONAHA.113.001719

159. Shang Q, Tam LS, Li EK, Yip GW, Yu CM. Increased arterial stiffness correlated with disease activity in systemic lupus erythematosus. Lupus. (2008) 17:1096-102. doi: 10.1177/0961203308092160

160. Yudkin JS, Stehouwer CD, Emeis JJ, Coppack SW. C-reactive protein in healthy subjects: associations with obesity, insulin resistance, and endothelial dysfunction: a potential role for cytokines originating from adipose tissue? Arterioscler Thromb Vasc Biol. (1999) 19:972-8. doi: 10.1161/01.ATV.19.4.972

161. van der Meer IM, de Maat MP, Bots ML, Breteler MM, Meijer J, Kiliaan AJ, et al. Inflammatory mediators and cell adhesion molecules as indicators of severity of atherosclerosis: the rotterdam study. Arterioscler Thromb Vasc Biol. (2002) 22:838-42. doi: 10.1161/01.ATV.0000016249.96529.B8

162. Xue H, Li JJ, Wang JL, Chen SH, Gao JS, Chen YD, et al. Changes in pulse pressure $\times$ heart rate, hs-CRP, and arterial stiffness progression in the Chinese general population: a cohort study involving 3978 employees of the Kailuan company. J Geriatr Cardiol. (2019) 16:710-6. doi: 10.11909/j.issn.1671-5411.2019.09.010

163. Park MY, Herrmann SM, Saad A, Eirin A, Tang H, Lerman A, et al. Biomarkers of kidney injury and klotho in patients with atherosclerotic renovascular disease. Clin J Am Soc Nephrol. (2015) 10:443-51. doi: 10.2215/CJN.07290714

164. Navarro-González JF, Donate-Correa J, Muros de Fuentes M, PérezHernández H, Martínez-Sanz R, Mora-Fernández C. Reduced KLOTHO is associated with the presence and severity of coronary artery disease. Heart. (2014) 100:34-40. doi: 10.1136/heartjnl-2013-304746

165. Chirinos JA, Sardana M, Syed AA, Koppula MR, Varakantam S, Vasim I, et al. Aldosterone, inactive matrix gla-protein, and large artery stiffness in hypertension. J Am Soc Hypertens. (2018) 12:681-9. doi: 10.1016/j.jash.2018.06.018

166. Lacolley P, Labat C, Pujol A, Delcayre C, Benetos A, Safar M. Increased carotid wall elastic modulus and fibronectin in aldosteronesalt-treated rats: effects of eplerenone. Circulation. (2002) 106:2848-53. doi: 10.1161/01.CIR.0000039328.33137.6C

167. Aragones G, Ferre R, Lazaro I, Cabre A, Plana N, Merino J, et al. Fatty acid-binding protein 4 is associated with endothelial dysfunction in patients with type 2 diabetes. Atherosclerosis. (2010) 213:329-31. doi: 10.1016/j.atherosclerosis.2010.07.026

168. Fuseya T, Furuhashi M, Yuda S, Muranaka A, Kawamukai M, Mita T, et al. Elevation of circulating fatty acid-binding protein 4 is independently associated with left ventricular diastolic dysfunction in a general population. Cardiovasc Diabetol. (2014) 13:126. doi: 10.1186/s12933-014-0126-7

169. von Eynatten M, Breitling LP, Roos M, Baumann M, Rothenbacher D, Brenner H. Circulating adipocyte fatty acid-binding protein levels and cardiovascular morbidity and mortality in patients with coronary heart disease: a 10-year prospective study. Arterioscler Thromb Vasc Biol. (2012) 32:2327-35. doi: 10.1161/ATVBAHA.112.248609

170. Chen MC, Hsu BG, Lee CJ, Yang CF, Wang JH. High serum adipocyte fatty acid binding protein level as a potential biomarker of aortic arterial stiffness in hypertensive patients with metabolic syndrome. Clin Chim Acta. (2017) 473:166-72. doi: 10.1016/j.cca.2017.08.030

171. Tseng PW, Hou JS, Wu DA, Hsu BG. High serum adipocyte fatty acid binding protein concentration linked with increased aortic arterial 
stiffness in patients with type 2 diabetes. Clin Chim Acta. (2019) 495:35-9. doi: 10.1016/j.cca.2019.03.1629

172. Vavruch C, Länne T, Fredrikson M, Lindström T, Östgren CJ, Nystrom FH. Serum leptin levels are independently related to the incidence of ischemic heart disease in a prospective study of patients with type 2 diabetes. Cardiovasc Diabetol. (2015) 14:62. doi: 10.1186/s12933-0150208-1

173. Montazerifar F, Bolouri A, Paghalea RS, Mahani MK, Karajibani M. Obesity. Serum resistin and leptin levels linked to coronary artery disease. Arq Bras Cardiol. (2016) 107:348-353. doi: 10.5935/abc.20160134

174. Tsai JP, Lee MC, Chen YC, Ho GJ, Shih MH, Hsu BG. Hyperleptinemia is a risk factor for the development of central arterial stiffness in kidney transplant patients. Transplant Proc. (2015) 47:1825-30. doi: 10.1016/j.transproceed.2015.06.002

175. Kuo CH, Lin YL, Wang CH, Lai YH, Syu RJ, Hsu BG. High serum leptin levels are associated with central arterial stiffness in geriatric patients on hemodialysis. Ci Ji Yi Xue Za Zhi. (2018) 30:227-32. doi: 10.4103/tcmj.tcmj_10_18

176. D’Elia L, Giaquinto A, De Luca F, Strazzullo P, Galletti F. Relationship between circulating leptin levels and arterial stiffness: a systematic review and meta-analysis of observational studies. High Blood Press Cardiovasc Prev. (2020) 27:505-13. doi: 10.1007/s40292-020-00404-y

177. Clerico A, Giannoni A, Vittorini S, Passino C. Thirty years of the heart as an endocrine organ: physiological role and clinical utility of cardiac natriuretic hormones. Am J Physiol Heart Circul Physiol. (2011) 301:H12-20. doi: 10.1152/ajpheart.00226.2011

178. Khan SQ, O’Brien RJ, Struck J, Quinn P, Morgenthaler N, Squire I, et al. Prognostic value of midregional pro-adrenomedullin in patients with acute myocardial infarction: the LAMP (leicester acute myocardial infarction peptide) study. J Am Coll Cardiol. (2007) 49:1525-32. doi: 10.1016/j.jacc.2006.12.038

179. O'Malley RG, Bonaca MP, Scirica BM, Murphy SA, Jarolim P, Sabatine MS, et al. Prognostic performance of multiple biomarkers in patients with non-ST-segment elevation acute coronary syndrome: analysis from the MERLIN-TIMI 36 trial (metabolic efficiency with ranolazine for less ischemia in non-ST-elevation acute coronary syndromes-thrombolysis in myocardial infarction 36). J Am Coll Cardiol. (2014) 63:1644-53. doi: 10.1016/j.jacc.2013.12.034

180. Klug G, Feistritzer HJ, Reinstadler SJ, Krauter L, Mayr A, Mair J, et al. Association of aortic stiffness with biomarkers of myocardial wall stress after myocardial infarction. Int J Cardiol. (2014) 173:253-8. doi: 10.1016/j.ijcard.2014.02.038

181. Reinstadler SJ, Feistritzer HJ, Klug G, Mayr A, Huybrechts L, HammererLercher A, et al. Biomarkers of hemodynamic stress and aortic stiffness after STEMI: a cross-sectional analysis. Dis Markers. (2015) 2015:717032. doi: $10.1155 / 2015 / 717032$

182. Hagstrom E, Michaelsson K, Melhus H, Hansen T, Ahlstrom H, Johansson L, et al. Plasma-parathyroid hormone is associated with subclinical and clinical atherosclerotic disease in 2 community-based cohorts. Arterioscler Thromb Vasc Biol. (2014) 34:1567-73. doi: 10.1161/ATVBAHA.113.303062

183. Schillaci G, Pucci G, Pirro M, Monacelli M, Scarponi AM, Manfredelli MR, et al. Large-artery stiffness: a reversible marker of cardiovascular risk in primary hyperparathyroidism. Atherosclerosis. (2011) 218:96-101. doi: 10.1016/j.atherosclerosis.2011.05.010

184. Cheng YB, Li LH, Guo QH, Li FK, Huang QF, Sheng CS, et al. Independent effects of blood pressure and parathyroid hormone on aortic pulse wave velocity in untreated Chinese patients. J Hypertens. (2017) 35:1841-8. doi: 10.1097/HJH.0000000000001395

185. Muse ED, Feldman DI, Blaha MJ, Dardari ZA, Blumenthal RS, Budoff $\mathrm{MJ}$, et al. The association of resistin with cardiovascular disease in the multi-ethnic study of atherosclerosis. Atherosclerosis. (2015) 239:101-8. doi: 10.1016/j.atherosclerosis.2014.12.044
186. Norman G, Norton GR, Gomes M, Michel F, Majane OH, Sareli P, et al. Circulating resistin concentrations are independently associated with aortic pulse wave velocity in a community sample. J Hypertens. (2016) 34:274-81. doi: 10.1097/HJH.0000000000000792

187. Wang JH, Lee CJ, Yang CF, Chen YC, Hsu BG. Serum resistin as an independent marker of aortic stiffness in patients with coronary artery disease. PLoS ONE. (2017) 12:e0183123. doi: 10.1371/journal.pone.0183123

188. Krishnan E, Baker JF, Furst DE, Schumacher HR. Gout and the risk of acute myocardial infarction. Arthritis Rheum. (2006) 54:2688-96. doi: 10.1002/art.22014

189. Verdecchia P, Schillaci G, Reboldi G, Santeusanio F, Porcellati C, Brunetti P. Relation between serum uric acid and risk of cardiovascular disease in essential hypertension. The PIUMA study. Hypertension. (2000) 36:1072-8. doi: 10.1161/01.HYP.36.6.1072

190. Bos MJ, Koudstaal PJ, Hofman A, Witteman JC, Breteler MM. Uric acid is a risk factor for myocardial infarction and stroke: the rotterdam study. Stroke. (2006) 37:1503-7. doi: 10.1161/01.STR.0000221716.55088.d4

191. Baena CP, Lotufo PA, Mill JG, Cunha Rde S, Bensenor IJ. Serum uric acid and pulse wave velocity among healthy adults: baseline data from the brazilian longitudinal study of adult health (ELSA-Brasil). Am J Hypertens. (2015) 28:966-70. doi: 10.1093/ajh/hpu298

192. Rebora P, Andreano A, Triglione N, Piccinelli E, Palazzini M, Occhi L, et al. Association between uric acid and pulse wave velocity in hypertensive patients and in the general population: a systematic review and metaanalysis. Blood Press. (2020) 29:220-31. doi: 10.1080/08037051.2020.1735929

193. Park JS, Kang S, Ahn CW, Cha BS, Kim KR, Lee HC. Relationships between serum uric acid, adiponectin and arterial stiffness in postmenopausal women. Maturitas. (2012) 73:344-8. doi: 10.1016/j.maturitas.2012.09.009

194. Mehta T, Nuccio E, McFann K, Madero M, Sarnak MJ, Jalal D. Association of uric acid with vascular stiffness in the framingham heart study. Am J Hypertens. (2015) 28:877-83. doi: 10.1093/ajh/hpu253

195. Boutouyrie P, Chowienczyk P, Humphrey JD, Mitchell GF. Arterial stiffness and cardiovascular risk in hypertension. Circ Res. (2021) 128:864-886. doi: 10.1161/CIRCRESAHA.121. 318061

196. Vlachopoulos C, Terentes-Printzios D, Laurent S, Nilsson PM, Protogerou $\mathrm{AD}$, Aznaouridis $\mathrm{K}$, et al. Association of estimated pulse wave velocity with survival: a secondary analysis of SPRINT. JAMA Netw Open. (2019) 2:e1912831. doi: 10.1001/jamanetworkopen.2019.12831

197. Nicholson CJ, Singh K, Saphirstein RJ, Gao YZ, Li Q, Chiu JG, et al. Reversal of aging-induced increases in aortic stiffness by targeting cytoskeletal protein-protein interfaces. J Am Heart Assoc. (2018) 7:e008926. doi: 10.1161/JAHA.118.008926

Conflict of Interest: The authors declare that the research was conducted in the absence of any commercial or financial relationships that could be construed as a potential conflict of interest.

Publisher's Note: All claims expressed in this article are solely those of the authors and do not necessarily represent those of their affiliated organizations, or those of the publisher, the editors and the reviewers. Any product that may be evaluated in this article, or claim that may be made by its manufacturer, is not guaranteed or endorsed by the publisher.

Copyright (๔) 2021 Angoff, Mosarla and Tsao. This is an open-access article distributed under the terms of the Creative Commons Attribution License (CC BY). The use, distribution or reproduction in other forums is permitted, provided the original author(s) and the copyright owner(s) are credited and that the original publication in this journal is cited, in accordance with accepted academic practice. No use, distribution or reproduction is permitted which does not comply with these terms. 